\title{
Imidazole Schiff base ligands: Synthesis, coordination complexes and biological activities
}

\author{
John McGinley ${ }^{\mathrm{a}, *}$, Malachy McCann ${ }^{\mathrm{a}}$, Kaijie $\mathrm{Ni}^{\mathrm{a}}$, Theresa Tallon ${ }^{\mathrm{a}}$, Kevin Kavanagh ${ }^{\mathrm{b}}$, Michael Devereux $^{\mathrm{c}}$, \\ Xiaomei Ma ${ }^{\mathrm{d}}$, Vickie McKee ${ }^{\mathrm{d}}$ \\ ${ }^{a}$ Department of Chemistry, National University of Ireland Maynooth, Maynooth, Co. Kildare, Ireland \\ ${ }^{\mathrm{b}}$ Department of Biology, National University of Ireland Maynooth, Maynooth, Co. Kildare, Ireland \\ ${ }^{\mathrm{c}}$ The Inorganic Pharmaceutical and Biomimetic Research Centre, Focas Research Institute, Dublin Institute of Technology, Camden Row, Dublin 8, Ireland \\ ${ }^{\mathrm{d}}$ Department of Chemistry, Loughborough University, Loughborough, Leicestershire LE11 3TU, United Kingdom
}

\section{A R T I C L E I N F O}

\section{Article history:}

Received 21 January 2013

Accepted 13 March 2013

Available online 21 March 2013

\section{Keywords:}

Imidazoles

Schiff bases

Metal complexes

X-ray

Antimicrobial

Galleria mellonella

\begin{abstract}
A B S T R A C T
1-(3-Aminopropyl)imidazole (Apim) reacts with salicylaldehyde and a selection of imidazole aldehydes and the resulting Schiff base ligands readily coordinate to $\mathrm{Zn}(\mathrm{II}), \mathrm{Cu}(\mathrm{II})$ and $\mathrm{Ag}(\mathrm{I})$ centres. X-ray crystal structures were obtained for two of the free ligands and also the $\mathrm{Ag}(\mathrm{I})$ complex of the Apim-salicylaldehyde ligand. Encouragingly, all of free ligands and most of their metal complexes are relatively non-toxic, in vivo, towards Galleria mellonella. Although the free ligands and the $\mathrm{Cu}(\mathrm{II})$ and $\mathrm{Zn}$ (II) complexes are inactive, in vitro, against a selection of microbial pathogens, most of the $\mathrm{Ag}(\mathrm{I})$ complexes exhibit moderate anti-bacterial activity and good anti-fungal activity.
\end{abstract}

(c) 2013 Elsevier Ltd. All rights reserved.

\section{Introduction}

In recent years, metal complexes comprising Schiff base ligands have been shown to exhibit significant anticancer, antiviral and antimicrobial activity [1-4]. Commercially available 1-(3-aminopropyl)imidazole (Apim) (Fig. 1) has recently been complexed to the $\mathrm{Ag}(\mathrm{I})$ ion and the structurally characterised complexes, $[\mathrm{Ag}(\mathrm{Apim})] \mathrm{ClO}_{4} \quad[5]$ and $[\mathrm{Ag}($ Apim $)](9-\mathrm{aca}) \cdot \mathrm{H}_{2} \mathrm{O}$ (9-acaH = 9-anthracenecarboxylic acid) [6], exhibit high antimicrobial activities, in vitro. In addition, metal complexes comprising Schiff base ligands derived from Apim have also attracted attention. For example, polymeric $\mathrm{Ag}(\mathrm{I})$ complexes of 3 (Fig. 1) show interesting structural and luminescent properties [7], whilst $\mathrm{Co}(\mathrm{II}), \mathrm{Ni}(\mathrm{II}), \mathrm{Cu}(\mathrm{II}), \mathrm{Zn}(\mathrm{II})$ and $\mathrm{Cd}(\mathrm{II})$ complexes of $\mathbf{2}$ have been screened for their ability to inhibit the growth of bacterial and fungal pathogens [8].

In the present paper we detail the synthesis, coordination chemistry, in vivo toxicity and antimicrobial activities of the uncoordinated Apim-derived Schiff base ligands 2-6 (Fig. 1) and their $\mathrm{Ag}(\mathrm{I}), \mathrm{Cu}(\mathrm{II})$ and $\mathrm{Zn}(\mathrm{II})$ complexes.

\footnotetext{
* Corresponding author. Tel.: +3531708 4615; fax: +35317083815.

E-mail address: john.mcginley@nuim.ie (J. McGinley).
}

\section{Experimental}

\subsection{Reagents and instrumentation}

${ }^{1} \mathrm{H}$ and ${ }^{13} \mathrm{C}$ NMR $(\delta$ ppm; $J \mathrm{~Hz}$ ) spectra were recorded on a BrukerAvance $300 \mathrm{MHz}$ NMR spectrometer using saturated $\mathrm{d}_{6}$-DMSO solutions with $\mathrm{Me}_{4} \mathrm{Si}$ reference, unless indicated otherwise, with resolutions of $0.18 \mathrm{~Hz}$ and $0.01 \mathrm{ppm}$, respectively. Infrared spectra $\left(\mathrm{cm}^{-1}\right)$ were recorded as $\mathrm{KBr}$ discs using a Perkin Elmer System2000 FT-IR spectrometer. UV-vis spectra were run on a Unicam UV 540 spectrometer. Melting point analyses were carried out using a Stewart Scientific SMP 1 melting point apparatus and are uncorrected. Electrospray (ESI) mass spectra were collected on an Agilent Technologies 6410 Time of Flight LC/MS. Compounds were dissolved in acetonitrile-water (1:1) solutions containing $0.1 \%$ formic acid, unless stated otherwise. The interpretation of mass spectra was made with the help of the program, "Agilent Masshunter Workstation Software". Magnetic susceptibility measurements were carried out at room temperature using a Johnson Matthey Magnetic Susceptibility Balance with $\left[\mathrm{HgCo}(\mathrm{SCN})_{4}\right]$ as reference. Microanalytical data were carried out using an Electron Corporation Thermo FlashEA 1112 Series analyser. Starting materials were commercially obtained and used without further purification. 


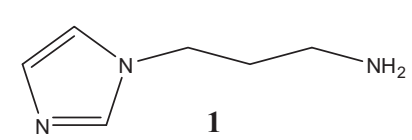<smiles>Oc1ccccc1/C=N/CCCn1ccnc1</smiles><smiles>C(=N/CCCn1ccnc1)\c1cnc[nH]1</smiles><smiles>C(=N/CCCn1ccnc1)\c1ncc[nH]1</smiles><smiles>Cc1nc[nH]c1/C=N/CCCn1ccnc1</smiles><smiles>Cn1ccnc1/C=N/CCCn1ccnc1</smiles>

Fig. 1. Structures of Apim (1) and its Schiff base derivatives, 2-6.

Caution! Although not encountered in our experiments, perchlorate salts of metal ions are potentially explosive and should be manipulated with care and used only in small quantities.

\subsection{Synthesis of ligands}

\subsubsection{2-([3-(1H-imidazol-1-}

yl)propyl]aminopropyliminomethyl)phenol (2)

This compound was prepared using a method similar to those previously reported [8,9]. To a solution of Apim (5.43 g, $43.4 \mathrm{mmol}$ ) in dry methanol $(30 \mathrm{~mL})$ was added salicylaldehyde $(5.30 \mathrm{~g}$, $43.4 \mathrm{mmol}$ ) with constant stirring. The resulting yellow solution was refluxed for $3 \mathrm{~h}$ and then stirred overnight at room temperature. The solvent was then removed under reduced pressure to give a yellow oil, which, on standing for $4 \mathrm{~h}$, yielded yellow crystals of $\mathbf{2}$. The crystals were recrystallised from toluene, filtered, washed with cold, dry methanol and air-dried (9.5 g, yield 95\%). M.p. 83-84 ${ }^{\circ} \mathrm{C}$ (lit. $78-80{ }^{\circ} \mathrm{C}$ ). $\mathrm{C}_{13} \mathrm{H}_{15} \mathrm{~N}_{3} \mathrm{O}$ (229.28): Calc. C, 68.10; H, 6.59; N, 18.33. Found: C, 68.23; H, 6.40; $\mathrm{N}, 18.24 \% .{ }^{1} \mathrm{H}$ NMR ( $d_{6}$-DMSO): $\delta=13.36(\mathrm{br} \mathrm{s}, 1 \mathrm{H}), 8.54(\mathrm{~s}, 1 \mathrm{H}), 7.64(\mathrm{~s}, 1 \mathrm{H}), 7.43(\mathrm{~d}, 1 \mathrm{H}$, $J=6.3 \mathrm{~Hz}), 7.34(\mathrm{t}, 1 \mathrm{H}, J=6.6 \mathrm{~Hz}), 7.21(\mathrm{~s}, 1 \mathrm{H}), 6.91(\mathrm{~m}, 3 \mathrm{H}), 4.05$ $(\mathrm{t}, 2 \mathrm{H}, J=6.9 \mathrm{~Hz}), 3.54(\mathrm{t}, 2 \mathrm{H}, J=6.9 \mathrm{~Hz}), 2.10(\mathrm{p}, 2 \mathrm{H}, J=6.9$, $7.2 \mathrm{~Hz}) \mathrm{ppm} .{ }^{13} \mathrm{C}$ NMR $\left(d_{6}\right.$-DMSO): $\delta=166.3,160.5,137.2,132.3$, 131.6, 128.5, 119.2, 118.6, 118.5, 116.4, 55.4, 43.8, 31.6 ppm. IR $(\mathrm{KBr}): v=3434,3101,1632,1576,1491,1401,1276,1225,1151$, 1079, 887, 808, $760 \mathrm{~cm}^{-1}$. LC/TCOF-MS: Calc. for $\mathrm{C}_{13} \mathrm{H}_{16} \mathrm{~N}_{3} \mathrm{O}$ $[\mathrm{M}+1]^{+}$230.3. Found: $230.1 \%$.

\subsection{2. $\mathrm{N}-[(\mathrm{E})-1 \mathrm{H}$-Imidazol-5-ylmethylidene]-N-[3-(1H-imidazol-1- yl)propyl lamine (3)}

This compound was prepared using a method similar to those previously reported [7]. To a solution of Apim (2.83 g, $22.6 \mathrm{mmol})$ in dry methanol (17 mL) was added 4(5)-imidazolecarboxaldehyde $(2.17 \mathrm{~g}, 22.6 \mathrm{mmol})$. The resulting light-yellow suspension was heated to reflux for $3 \mathrm{~h}$ and the yellow solution was then stirred overnight at room temperature. The solvent was removed under reduced pressure to give an orange-yellow oil, which, on standing for $2 \mathrm{~h}$, yielded the orange-yellow solid (3). The solid was recrystallised from hot ethanol, filtered, washed with cold, dry ethanol and air-dried ( $4.3 \mathrm{~g}$, yield $94 \%$ ). M.p. $178-180^{\circ} \mathrm{C}$ (lit. $180-182^{\circ} \mathrm{C}$ ). $\mathrm{C}_{10} \mathrm{H}_{13} \mathrm{~N}_{5}(203.24)$ : Calc. C, 59.09; H, 6.45; N, 34.46. Found: C, 59.14; H, 6.28; N, 34.46\%. ${ }^{1} \mathrm{H}$ NMR $\left(d_{6}\right.$-DMSO): $\delta=12.59$ (br s, $1 \mathrm{H}), 8.19(\mathrm{~s}, 1 \mathrm{H}), 7.74(\mathrm{~s}, 1 \mathrm{H}), 7.63(\mathrm{~s}, 1 \mathrm{H}), 7.19(\mathrm{~s}, 1 \mathrm{H}), 6.90(\mathrm{~s}$, $1 \mathrm{H}), 4.03(\mathrm{t}, 2 \mathrm{H}, J=6.9 \mathrm{~Hz}), 3.42(\mathrm{t}, 2 \mathrm{H}, J=6.6 \mathrm{~Hz}), 2.01(\mathrm{p}, 2 \mathrm{H}$, $J=6.9,6.6 \mathrm{~Hz}) \mathrm{ppm} .{ }^{13} \mathrm{C}$ NMR $\left(d_{6}\right.$-DMSO $): \delta=137.2,128.4,119.2$, 57.2, 43.9, 31.9 ppm. IR (KBr): $v=3436,3137,3103,2844,1647$, $1509,1429,1355,1307,1236,1220,1111,1081,1026,827$. $749 \mathrm{~cm}^{-1}$. LC/TCOF-MS: Calc. for $\mathrm{C}_{10} \mathrm{H}_{14} \mathrm{~N}_{5}[\mathrm{M}+1]^{+}$204.2. Found: $204.1 \%$.
2.2.3. $\mathrm{N}$-[(E)-1H-Imidazol-2-ylmethylidene]-N-[3-(1H-imidazol-1yl)propyl]amine (4)

To a solution of Apim $(2.81 \mathrm{~g}, 22.5 \mathrm{mmol})$ in dry methanol $(17 \mathrm{~mL})$ was added imidazole-2-carboxaldehyde (2.17 g, $22.5 \mathrm{mmol}$ ). The resulting solution was heated to reflux for $3 \mathrm{~h}$ and then stirred overnight at room temperature. The solvent was removed under reduced pressure to give a brown oil, which, on standing for 2 months, yielded the orange-brown solid (4) (3.69 g, yield 86\%). M.p. $44-46{ }^{\circ} \mathrm{C} . \mathrm{C}_{10} \mathrm{H}_{13} \mathrm{~N}_{5} \cdot 0.5 \mathrm{H}_{2} \mathrm{O}$ (212.15): Calc. C, 56.56; H, 6.59; N, 33.01. Found: C, 56.08; H, 6.32; N, 32.87\%. ${ }^{1} \mathrm{H}$ NMR $\left(d_{6}\right.$-DMSO): $\delta=8.17(\mathrm{~s}, 1 \mathrm{H}), 7.65(\mathrm{~s}, 1 \mathrm{H}), 7.19(\mathrm{~s}, 1 \mathrm{H}), 7.13(\mathrm{~s}$, $1 \mathrm{H}), 7.11(\mathrm{~s}, 1 \mathrm{H}), 6.91(\mathrm{~s}, 1 \mathrm{H}), 4.06(\mathrm{t}, 2 \mathrm{H}, J=6.9 \mathrm{~Hz}), 3.43(\mathrm{t}, 2 \mathrm{H}$, $J=6.0 \mathrm{~Hz}), 2.01(\mathrm{t}, 2 \mathrm{H}, J=6.9 \mathrm{~Hz}) \mathrm{ppm} .{ }^{13} \mathrm{C}$ NMR $\left(d_{6}\right.$-DMSO): $\delta=152.3,144.4,137.2,128.2,119.4,56.7,43.9,31.7$ ppm. IR $(\mathrm{KBr}): v=3114,1650,1513,1446,1397,1232,1109,1083$, $771 \mathrm{~cm}^{-1}$. LC/TCOF-MS: Calc. for $\mathrm{C}_{10} \mathrm{H}_{14} \mathrm{~N}_{5}[\mathrm{M}+1]^{+}$204.2. Found: $204.1 \%$.

\subsubsection{3-(1H-Imidazol-1-yl)-N-[(E)-(5-methyl-1H-imidazol-4-}

yl)methylidene]-1-propanamine (5)

To a solution of Apim $(2.81 \mathrm{~g}, 22.5 \mathrm{mmol})$ in dry methanol $(17 \mathrm{~mL})$ was added 4-methyl-5-imidazolecarboxaldehyde $(2.17 \mathrm{~g}$, $22.5 \mathrm{mmol}$ ). The resulting light-yellow suspension was heated to reflux for $3 \mathrm{~h}$. The suspension was dissolved completely after $5 \mathrm{~min}$. The solution was then stirred overnight at room temperature. After $0.5 \mathrm{~h}$ the solution turned orange in colour. The solvent was removed under reduced pressure to give an orange oil, which, on standing for 3 weeks, yielded the orange solid (5) (3.10 g, yield 76\%). M.p. $113-115{ }^{\circ} \mathrm{C} . \mathrm{C}_{11} \mathrm{H}_{15} \mathrm{~N}_{5}$ (217.27): Calc. C, 60.81; H, 6.96; $\mathrm{N}, 32.23$. Found: $\mathrm{C}, 60.60 ; \mathrm{H}, 6.72 ; \mathrm{N}, 31.35 \% .{ }^{1} \mathrm{H}$ NMR $\left(d_{6}\right.$-DMSO): $\delta=8.23(\mathrm{~s}, 1 \mathrm{H}), 7.64(\mathrm{~s}, 1 \mathrm{H}), 7.61(\mathrm{~s}, 1 \mathrm{H}), 7.18(\mathrm{~s}, 1 \mathrm{H}), 6.91(\mathrm{~s}, 1 \mathrm{H})$, $4.04(\mathrm{t}, 2 \mathrm{H}, J=7.2 \mathrm{~Hz}), 3.42(\mathrm{t}, 2 \mathrm{H}, J=6.6 \mathrm{~Hz}), 2.32(\mathrm{~s}, 3 \mathrm{H}), 2.03(\mathrm{p}$, $2 \mathrm{H}, J=6.9,6.6 \mathrm{~Hz}) \mathrm{ppm} .{ }^{13} \mathrm{C}$ NMR $\left(d_{6}\right.$-DMSO): $\delta=137.2,128.3$, 119.3, 57.3, 48.5, 43.9, $32.1 \mathrm{ppm}$. IR (KBr): $v=3113,1643,1529$, 1452, 1395, 1354, 1233, 1110, 1082, 826, $747 \mathrm{~cm}^{-1}$. LC/TCOF-MS: Calc. for $\mathrm{C}_{10} \mathrm{H}_{14} \mathrm{~N}_{5}[\mathrm{M}+1]^{+}$218.3. Found 218.1\%.

\subsubsection{3-(1H-Imidazol-1-yl)-N-[(E)-(1-methyl-1H-imidazol-2-} yl)methylidene -1 -propanamine $(\mathbf{6})$

To a solution of Apim $(2.81 \mathrm{~g}, 22.5 \mathrm{mmol})$ in dry methanol $(17 \mathrm{~mL})$ was added 1-methyl-2-imidazolecarboxaldehyde $(2.47 \mathrm{~g}$, $22.5 \mathrm{mmol}$ ). The resulting light-yellow solution was refluxed for $3 \mathrm{~h}$ and then stirred overnight at room temperature. After $0.5 \mathrm{~h}$ the solution turned orange in colour. The solvent was removed under reduced pressure to give the yellow oil (6) (3.11 g, yield 73\%). $\mathrm{C}_{11} \mathrm{H}_{15} \mathrm{~N}_{5}$ (217.27): Calc. C, 60.81; H, 6.96; N, 32.23. Found: C, $60.20 ; \mathrm{H}, 6.35 ; \mathrm{N}, 31.83 \% .{ }^{1} \mathrm{H}$ NMR $\left(d_{6}\right.$-DMSO): $\delta=8.25(\mathrm{~s}, 1 \mathrm{H})$, $7.64(\mathrm{~s}, 1 \mathrm{H}), 7.30(\mathrm{~s}, 1 \mathrm{H}), 7.20(\mathrm{~s}, 1 \mathrm{H}), 7.04(\mathrm{~s}, 1 \mathrm{H}), 6.90(\mathrm{~s}, 1 \mathrm{H})$, $4.07(\mathrm{t}, 2 \mathrm{H}, J=7.5 \mathrm{~Hz}), 3.92(\mathrm{~s}, 3 \mathrm{H}), 3.51(\mathrm{t}, 2 \mathrm{H}, J=6.9 \mathrm{~Hz}), 2.05$ $(\mathrm{p}, 2 \mathrm{H}, J=6.9,6.9 \mathrm{~Hz}) \mathrm{ppm} .{ }^{13} \mathrm{C}$ NMR $\left(d_{6}\right.$-DMSO): $\delta=153.6,142.3$, 
$137.2,128.5,128.3,125.6,119.3,57.6,43.9,34.9,31.8$ ppm. IR $(\mathrm{KBr}): v=3371,3112,1651,1509,1480,1439,1289,1231,1151$, 1082, $774 \mathrm{~cm}^{-1}$. LC/TCOF-MS: Calc. for $\mathrm{C}_{10} \mathrm{H}_{14} \mathrm{~N}_{5}[\mathrm{M}+1]^{+} 218.3$. Found: $218.2 \%$.

\subsection{General synthesis of silver(I) complexes}

All of the $\mathrm{Ag}(\mathrm{I})$ complexes were synthesised with the exclusion of light and samples were stored in the dark. To a solution of the appropriate ligand $(6.07 \mathrm{mmol})$ in dry methanol $(47 \mathrm{~mL})$ was added, dropwise, a solution of $\mathrm{AgClO}_{4}(2.89 \mathrm{mmol})$ in dry methanol $(5 \mathrm{~mL})$ with constant stirring. The white suspension was then stirred for $2 \mathrm{~h}$ at room temperature. The solid was removed by filtration and washed with cold methanol to yield either white or pale-coloured solids, which were recrystallised from either hot acetonitrile or hot ethanol and air-dried.

\subsection{1. $\left[\mathrm{Ag}(\boldsymbol{2})_{2}\right] \mathrm{ClO}_{4}$}

Pale yellow solid recrystallised from hot acetonitrile $(1.48 \mathrm{~g}$, yield 77\%). $\mathrm{C}_{26} \mathrm{H}_{30} \mathrm{AgClN}_{6} \mathrm{O}_{6}$ (665.88): Calc. C, 46.90; $\mathrm{H}, 4.54 ; \mathrm{N}$, 12.62. Found: $\mathrm{C}, 46.34 ; \mathrm{H}, 4.37$; $\mathrm{N}, 13.14 \% .{ }^{1} \mathrm{H}$ NMR $\left(d_{6}\right.$-DMSO): $\delta=13.28($ br s, 2H), $8.55(\mathrm{~s}, 2 \mathrm{H}), 8.07(\mathrm{~s}, 2 \mathrm{H}), 7.50(\mathrm{~d}, 2 \mathrm{H}$, $J=1.2 \mathrm{~Hz}), 7.46(\mathrm{~s}, 2 \mathrm{H}), 7.34(\mathrm{~m}, 2 \mathrm{H}), 7.12(\mathrm{~m}, 2 \mathrm{H}), 6.91(\mathrm{~m}, 2 \mathrm{H})$, $4.18(\mathrm{t}, 4 \mathrm{H}, J=6.9 \mathrm{~Hz}), 3.58(\mathrm{t}, 4 \mathrm{H}, J=6.6 \mathrm{~Hz}), 2.16(\mathrm{t}, 4 \mathrm{H}$, $J=6.9 \mathrm{~Hz})$ ppm. ${ }^{13} \mathrm{C}$ NMR $\left(d_{6}\right.$-DMSO): $\delta=166.4,160.4,139.1$, $132.3,131.6,129.1,120.2,118.6,118.5,116.4,55.4,44.8$, $31.3 \mathrm{ppm}$. IR (KBr): $v=3432,3138,1633,1579,1499,1393,1278$, 1240, 1089, 837, $766 \mathrm{~cm}^{-1}$. LC/TCOF-MS: Calc. for $\mathrm{C}_{26} \mathrm{H}_{30} \mathrm{AgN}_{6} \mathrm{O}_{2}$ $\left[\mathrm{Ag}(2)_{2}\right]^{+}$567.2, found 567.1; Calc. for $\mathrm{C}_{13} \mathrm{H}_{15} \mathrm{AgN}_{3} \mathrm{O}[\mathrm{Ag}(2)]^{+}$ 336.1. Found: $336.0 \%$. Solubility: $\mathrm{MeOH}$ (hot), EtOH (hot), MeCN, $\mathrm{CHCl}_{3}$, DMSO.

\subsection{2. $[\mathrm{Ag}(\mathbf{3})] \mathrm{ClO}_{4}$}

White solid (0.66 g, yield 28\%). $\mathrm{C}_{10} \mathrm{H}_{13} \mathrm{AgClN}_{5} \mathrm{O}_{4}$ (410.56): Calc. C, 29.25; H, 3.19; N, 17.06. Found: C, 29.29; H, 3.05; N, 17.23\%. ${ }^{1} \mathrm{H}$ NMR $\left(d_{6}\right.$-DMSO): $\delta=13.16(\mathrm{br} s, 1 \mathrm{H}), 8.52(\mathrm{~s}, 1 \mathrm{H}), 8.24(\mathrm{~s}$, 1H), $7.96(\mathrm{~s}, 1 \mathrm{H}), 7.88(\mathrm{~s}, 1 \mathrm{H}), 7.44(\mathrm{~s}, 1 \mathrm{H}), 7.11(\mathrm{~s}, 1 \mathrm{H}), 4.12(\mathrm{t}$, $2 \mathrm{H}, J=7.8 \mathrm{~Hz}), 3.67(\mathrm{t}, 2 \mathrm{H}, J=5.7 \mathrm{~Hz}), 2.06(\mathrm{t}, 2 \mathrm{H}, J=8.1 \mathrm{~Hz}) \mathrm{ppm}$. ${ }^{13} \mathrm{C}$ NMR $\left(d_{6}\right.$-DMSO): $\delta=155.2,138.9,138.6,136.4,129.2,122.3$, $120.5,55.5,44.8,32.4 \mathrm{ppm}$. IR $(\mathrm{KBr}): v=3252,3130,2952$, 2854, 1648, 1519, 1447, 1298, $757 \mathrm{~cm}^{-1}$. LC/TCOF-MS: Calc. for $\mathrm{C}_{10} \mathrm{H}_{13} \mathrm{AgN}_{5}[\mathrm{Ag}(3)]^{+} 310.1$, found 310.0; Calc. for $\mathrm{C}_{20} \mathrm{H}_{26} \mathrm{AgN}_{10}$ $\left[\operatorname{Ag}(3)_{2}\right]^{+}$513.3. Found: $513.1 \%$. Solubility: DMSO.

\subsection{3. $[\mathrm{Ag}(\mathbf{4})] \mathrm{ClO}_{4}$}

Pale-orange solid (0.56 g, yield $22 \%$ ). $\mathrm{C}_{10} \mathrm{H}_{13} \mathrm{AgClN}_{5} \mathrm{O}_{4}$ (410.56): Calc. C, 29.25; H, 3.19; N, 17.06. Found: C, 29.56; H, 3.54; N, 16.41\%. ${ }^{1} \mathrm{H}$ NMR $\left(d_{6}\right.$-DMSO): $\delta=8.39(\mathrm{~s}, 1 \mathrm{H}), 7.94(\mathrm{~s}, 1 \mathrm{H}), 7.50(\mathrm{~s}, 1 \mathrm{H}), 7.47$ $(\mathrm{s}, 1 \mathrm{H}), 7.42(\mathrm{~s}, 1 \mathrm{H}), 7.17(\mathrm{~s}, 1 \mathrm{H}), 4.12(\mathrm{t}, 2 \mathrm{H}, J=7.2 \mathrm{~Hz}), 3.70(\mathrm{t}, 2 \mathrm{H}$, $J=6.6 \mathrm{~Hz}), 2.06(\mathrm{t}, 2 \mathrm{H}, J=7.4 \mathrm{~Hz}) \mathrm{ppm} .{ }^{13} \mathrm{C}$ NMR $\left(d_{6}\right.$-DMSO): $\delta=181.1,152.3,145.5,144.4,137.3,129.1,128.2,119.4,56.7$, 43.9, 31.7 ppm. IR (KBr): $v=3313,3129,2939,1645,1520,1448$, 1240, 1108, 834, $766 \mathrm{~cm}^{-1}$. LC/TCOF-MS: Calc. for $\mathrm{C}_{10} \mathrm{H}_{13} \mathrm{AgN}_{5}$ $[\mathrm{Ag}(\mathbf{4})]^{+}$310.2, found 310.0; Calc. for $\mathrm{C}_{20} \mathrm{H}_{26} \mathrm{AgN}_{10}\left[\mathrm{Ag}(\mathbf{4})_{2}\right]^{+}$ 513.3. Found: $513.1 \%$. Solubility: DMSO.

\subsection{4. $[\mathrm{Ag}(\mathbf{5})] \mathrm{ClO}_{4}$}

White solid (1.26 g, yield 52\%). $\mathrm{C}_{11} \mathrm{H}_{15} \mathrm{AgClN}_{5} \mathrm{O}_{4}$ (424.59): Calc. C, 31.12; H, 3.56; N, 16.49. Found: C, 30.50; H, 3.30; N, 16.52\%. ${ }^{1} \mathrm{H}$ NMR $\left(d_{6}\right.$-DMSO): $\delta=12.99($ br s, $1 \mathrm{H}), 8.58(\mathrm{~s}, 1 \mathrm{H}), 8.09(\mathrm{~s}, 1 \mathrm{H})$, $7.96(\mathrm{~s}, 1 \mathrm{H}), 7.43(\mathrm{~s}, 1 \mathrm{H}), 7.11(\mathrm{~s}, 1 \mathrm{H}), 4.11(\mathrm{t}, 2 \mathrm{H}, J=8.4 \mathrm{~Hz}), 3.67$ (t, $2 \mathrm{H}, J=6.6 \mathrm{~Hz}), 2.39(\mathrm{~s}, 3 \mathrm{H}), 2.07$ (p, $2 \mathrm{H}, J=6.9,7.4 \mathrm{~Hz}) \mathrm{ppm}$. ${ }^{13} \mathrm{C}$ NMR $\left(d_{6}\right.$-DMSO): $\delta=154.6,138.6,137.8,132.2,129.2,120.5$, $55.5,44.8,32.5,8.6 \mathrm{ppm}$. IR (KBr): $v=3259,2928,1643,1519$, 1453, 1343, 1240, 1107, 996, 840, 804, $738 \mathrm{~cm}^{-1}$. LC/TCOF-MS:
Calc. for $\mathrm{C}_{11} \mathrm{H}_{15} \mathrm{AgN}_{5}[\operatorname{Ag}(\mathbf{5})]^{+}$324.1. Found: $324.0 \%$. Solubility: DMSO.

\subsection{5. $[\mathrm{Ag}(\mathbf{6})] \mathrm{ClO}_{4}$}

White solid (1.84 g, yield 75\%). $\mathrm{C}_{11} \mathrm{H}_{15} \mathrm{AgClN}_{5} \mathrm{O}_{4}$ (424.59): Calc. C, 31.12; H, 3.56; N, 16.49. Found: C, 31.42; H, 3.45; N, 16.03\%. ${ }^{1} \mathrm{H}$ NMR $\left(d_{6}\right.$-DMSO): $\delta=8.67(\mathrm{~s}, 1 \mathrm{H}), 7.95(\mathrm{~s}, 1 \mathrm{H}), 7.64(\mathrm{~s}, 1 \mathrm{H})$, $7.43(\mathrm{~s}, 1 \mathrm{H}), 7.32(\mathrm{~s}, 1 \mathrm{H}), 7.11(\mathrm{~s}, 1 \mathrm{H}), 4.12(\mathrm{t}, 2 \mathrm{H}, J=7.5 \mathrm{~Hz}), 3.95$ $(\mathrm{s}, 3 \mathrm{H}), 3.75(\mathrm{t}, 2 \mathrm{H}, J=5.7 \mathrm{~Hz}), 2.08(\mathrm{t}, 2 \mathrm{H}, J=7.2 \mathrm{~Hz}) \mathrm{ppm} .{ }^{13} \mathrm{C}$ NMR $\left(d_{6}\right.$-DMSO): $\delta=150.2,142.8,138.7,129.3,129.2,126.1$, $120.5,55.9,44.8,32.5,31.9$ ppm. IR $(\mathrm{KBr}): v=3448,3123,2940$, 1635, 1516, 1492, 1449, 1426, 1327, 1292, 1248, 1074, 948, 818, 780, $701 \mathrm{~cm}^{-1}$. LC/TCOF-MS: Calc. for $\mathrm{C}_{11} \mathrm{H}_{15} \mathrm{AgN}_{5}[\mathrm{Ag}(\mathbf{6})]^{+} 324.1$. Found: $324.0 \%$. Solubility: DMSO.

\subsection{General synthesis of copper(II) complexes}

To a solution of the appropriate ligand $(2.18 \mathrm{mmol})$ in dry methanol $(17 \mathrm{~mL})$ was added, dropwise, a solution of $\mathrm{Cu}\left(\mathrm{ClO}_{4}\right)_{2} \cdot 6 \mathrm{H}_{2} \mathrm{O}(0.55 \mathrm{mmol})$ in dry methanol $(2 \mathrm{~mL})$ with constant stirring. The green suspension was then stirred for $3 \mathrm{~h}$ at room temperature. The resulting solid was removed by filtration and washed with cold ethanol and air-dried to yield either a green or a blue solid.

\subsection{1. $\left[\mathrm{Cu}(\mathbf{2})_{4}\right]\left(\mathrm{ClO}_{4}\right)_{2}$}

Dark green solid (0.22 g, yield 48\%). $\mathrm{C}_{52} \mathrm{H}_{60} \mathrm{Cl}_{2} \mathrm{CuN}_{12} \mathrm{O}_{12}$ (1179.56): Calc. C, 52.95; H, 5.13; N, 14.25. Found: C, 53.19; H, 4.90; N, 13.69\%. IR (KBr): $v=3446,3130,1622,1539,1450,1404$, 1329, 1278, 1237, 1203, 1092, 833, $759 \mathrm{~cm}^{-1}$. LC/TCOF-MS: Calc. for $\mathrm{C}_{26} \mathrm{H}_{29} \mathrm{CuN}_{6} \mathrm{O}_{2}\left[\mathrm{Cu}(2)_{2}\right]^{+}$521.1. Found: 521.2\%. $\mu_{\text {eff: }} 2.53$ B.M. Solubility: MeCN (hot), DMSO.

\subsection{2. $\left[\mathrm{Cu}(3)_{2}\right]\left(\mathrm{ClO}_{4}\right)_{2} \cdot \mathrm{H}_{2} \mathrm{O}$}

Green solid (0.42 g, yield 50\%). $\mathrm{C}_{20} \mathrm{H}_{28} \mathrm{Cl}_{2} \mathrm{CuN}_{10} \mathrm{O}_{9}$ (686.95): Calc. C, 34.97; H, 4.10; N, 20.39. Found: C, 34.51; H, 3.93; N, 19.79\%. IR $(\mathrm{KBr}): v=3132,2945,1643,1521,1456,1346,1297,1239,1092$, 830, $752 \mathrm{~cm}^{-1}$. LC/TCOF-MS: Calc. for $\mathrm{C}_{20} \mathrm{H}_{26} \mathrm{CuN}_{10}\left[\mathrm{Cu}(3)_{2}\right]^{+}$ 469.2. Found: $469.2 \%$. $\mu_{\text {eff: }} 1.93$ B.M. Solubility: DMSO.

\subsection{3. $\left[\mathrm{Cu}(4)_{2}\right]\left(\mathrm{ClO}_{4}\right)_{2}$}

Light-green solid (0.42 g, yield 51\%). $\mathrm{C}_{20} \mathrm{H}_{26} \mathrm{Cl}_{2} \mathrm{CuN}_{10} \mathrm{O}_{8}$ (668.94): Calc. C, 35.91; H, 3.91; N, 20.94. Found: C, 36.13; H, 3.88; N, 20.60\%. IR (KBr): $v=3384,3123,2939,1621,1524$, 1455, 1237, 1089, 1027, 951, $762 \mathrm{~cm}^{-1}$. LC/TCOF-MS: Calc. for $\left.\mathrm{C}_{20} \mathrm{H}_{27} \mathrm{Cl}_{2} \mathrm{CuN}_{10} \mathrm{O}_{8}\left[\mathrm{Cu}(4)_{2}\right]\left(\mathrm{ClO}_{4}\right)_{2}+\mathrm{H}\right]^{+}$669.8. Found: 669.1\%. $\mu_{\text {eff }}$ : 1.97 B.M. Solubility: DMSO.

\subsection{4. $\left[\mathrm{Cu}(5)_{2}\right]\left(\mathrm{ClO}_{4}\right)_{2}$}

Blue solid ( $0.48 \mathrm{~g}$, yield $60 \%) . \mathrm{C}_{22} \mathrm{H}_{30} \mathrm{Cl}_{2} \mathrm{CuN}_{10} \mathrm{O}_{8}$ (696.99): Calc. C, 37.91; H, 4.34; N, 20.10. Found: C, 38.09; H, 4.33; N, 19.67\%. IR $(\mathrm{KBr}): v=3267,3139,2946,1635,1579,1518,1451,1352,1314$, 1280, 1239, 1099, 956, 827, $735 \mathrm{~cm}^{-1}$. LC/TCOF-MS: Calc. for $\mathrm{C}_{11} \mathrm{H}_{15} \mathrm{CuN}_{5}[\mathrm{Cu}(5)]^{+} 280.8$, found 280.1; Calc. for $\mathrm{C}_{22} \mathrm{H}_{30} \mathrm{CuN}_{10}$ $\left[\mathrm{Cu}(\mathbf{5})_{2}\right]^{+}$497.2. Found: 497.2\%. $\mu_{\text {eff: }}$ 1.90 B.M. Solubility: DMSO.

\subsection{5. $\left[\mathrm{Cu}(\mathbf{6})_{2}\right]\left(\mathrm{ClO}_{4}\right)_{2} \cdot \mathrm{H}_{2} \mathrm{O}$}

Light-blue solid (0.52 g, yield $65 \%$ ). $\mathrm{C}_{22} \mathrm{H}_{32} \mathrm{Cl}_{2} \mathrm{CuN}_{10} \mathrm{O}_{9}$ (715.0): Calc. C, 36.95; H, 4.51; N, 19.58. Found: C, 36.35; H, 4.31; N, $18.85 \%$. IR (KBr): $v=3436,3144,2950,1633,1523,1485,1452$, 1418, 1359, 1289, 1239, 1095, 950, 827, $769 \mathrm{~cm}^{-1}$. LC/TCOF-MS: Calc. for $\mathrm{C}_{22} \mathrm{H}_{30} \mathrm{CuN}_{10}\left[\mathrm{Cu}(\mathbf{6})_{2}\right]^{+}$497.2. Found: $497.2 \%$. $\mu_{\text {eff }}: 1.91$ B.M. Solubility: DMSO. 


\subsection{General synthesis of zinc(II) complexes}

To a solution of the appropriate ligand $(2.18 \mathrm{mmol})$ in dry methanol $(17 \mathrm{~mL})$ was added, dropwise, a solution of $\mathrm{Zn}\left(\mathrm{ClO}_{4}\right)_{2} \cdot 6 \mathrm{H}_{2} \mathrm{O}(0.55 \mathrm{mmol})$ in dry methanol $(5 \mathrm{~mL})$ with constant stirring. The suspension was then stirred for $2 \mathrm{~h}$ at room temperature. The resulting solid was removed by filtration and washed with cold ethanol and air-dried to yield either stiff oils or solids.

\subsection{1. $\left[\mathrm{Zn}(\mathbf{2})\left(\mathbf{2}^{-}\right)\right] \mathrm{ClO}_{4}$}

Stiff, yellow oil $(0.22 \mathrm{~g}$, yield $65 \%) . \mathrm{C}_{26} \mathrm{H}_{29} \mathrm{ClN}_{6} \mathrm{O}_{6} \mathrm{Zn}(622.38)$ : Calc. C, 50.17; H, 4.70; N, 13.50. Found: C, 50.27; H, 4.77; N, 12.78\%. ${ }^{1} \mathrm{H}$ NMR $\left(d_{6}\right.$-DMSO): $\delta=13.29$ (br s, $\left.1 \mathrm{H}\right), 8.54(\mathrm{~s}, 2 \mathrm{H})$, $8.02(\mathrm{~s}, 2 \mathrm{H}), 7.43(\mathrm{~d}, 2 \mathrm{H}, J=6.6 \mathrm{~Hz}), 7.34(\mathrm{t}, 2 \mathrm{H}, J=7.8 \mathrm{~Hz}), 7.06$ $(\mathrm{s}, 2 \mathrm{H}), 6.89(\mathrm{~m}, 4 \mathrm{H}), 4.14(\mathrm{t}, 4 \mathrm{H}, J=7.2 \mathrm{~Hz}), 3.57(\mathrm{t}, 4 \mathrm{H}$, $J=6.6 \mathrm{~Hz}), 2.14(\mathrm{t}, 4 \mathrm{H}, J=6.9 \mathrm{~Hz}) \mathrm{ppm}$. IR $(\mathrm{KBr}): v=3430,3102$, $2935,1633,1578,1492,1459,1401,1277,1225,1151,1080$, 809, $760 \mathrm{~cm}^{-1}$. LC/TCOF-MS: Calc. for $\mathrm{C}_{26} \mathrm{H}_{29} \mathrm{ZnN}_{6} \mathrm{O}_{2}\left[\mathrm{Zn}(\mathbf{2})\left(\mathbf{2}^{-}\right)\right]^{+}$ 521.3. Found: $521.2 \%$. Solubility: MeCN, DMSO.

\subsection{2. $\left[\mathrm{Zn}(3)_{2}\right]\left(\mathrm{ClO}_{4}\right)_{2}$}

White solid (0.54 g, yield 66\%). $\mathrm{C}_{20} \mathrm{H}_{26} \mathrm{Cl}_{2} \mathrm{~N}_{10} \mathrm{O}_{8} \mathrm{Zn}$ (670.77): Calc. C, 35.81; H, 3.91; N, 20.88. Found: C, 36.20; H, 3.86; N, $20.16 \% .{ }^{1} \mathrm{H}$ NMR $\left(d_{6}\right.$-DMSO): $\delta=8.47(\mathrm{~s}, 2 \mathrm{H}), 7.91(\mathrm{~s}, 2 \mathrm{H}), 7.63(\mathrm{~s}$, $2 \mathrm{H}), 7.14(\mathrm{~s}, 2 \mathrm{H}), 6.86(\mathrm{~s}, 2 \mathrm{H}), 3.88(\mathrm{t}, 4 \mathrm{H}, J=7.5 \mathrm{~Hz}), 3.30(\mathrm{t}, 2 \mathrm{H}$, $J=6.6 \mathrm{~Hz}), 1.70(\mathrm{t}, 2 \mathrm{H}, J=6.8 \mathrm{~Hz}) \mathrm{ppm}$. IR $(\mathrm{KBr}): v=3332,3144$, 2954, 2867, 1645, 1527, 1452, 1299, 1236, 1111, 847, $759 \mathrm{~cm}^{-1}$. LC/TCOF-MS: Calc. for $\mathrm{C}_{10} \mathrm{H}_{14} \mathrm{~N}_{5}$ [ligand+1] ${ }^{+}$204.2. Found: $204.1 \%$. Solubility: DMSO.

\subsection{3. $\left[\mathrm{Zn}(4)_{2}\right]\left(\mathrm{ClO}_{4}\right)_{2} \cdot \mathrm{H}_{2} \mathrm{O}$}

Light-orange solid $(0.31 \mathrm{~g}$, yield $60 \%) . \quad \mathrm{C}_{20} \mathrm{H}_{28} \mathrm{Cl}_{2} \mathrm{~N}_{10} \mathrm{O}_{9} \mathrm{Zn}$ (688.81): Calc. C, 34.87; H, 4.10; N, 20.33. Found: C, 35.16; H, 3.71; N, 19.63\%. ${ }^{1} \mathrm{H}$ NMR $\left(d_{6}\right.$-DMSO): $\delta=8.23(\mathrm{~s}, 2 \mathrm{H}), 7.89(\mathrm{~s}, 2 \mathrm{H})$, 7.33 (s, 2H), $7.29(\mathrm{~s}, 2 \mathrm{H}), 7.00(\mathrm{~s}, 2 \mathrm{H}), 4.01(\mathrm{t}, 4 \mathrm{H}, J=7.2 \mathrm{~Hz}), 3.40$ $(\mathrm{t}, 2 \mathrm{H}, J=6.8 \mathrm{~Hz}), 1.83(\mathrm{t}, 2 \mathrm{H}, J=7.0 \mathrm{~Hz}) \mathrm{ppm}$. IR $(\mathrm{KBr}): v=3134$ 2940, 1644, 1527, 1455, 1241, 1101, 954, $767 \mathrm{~cm}^{-1}$. LC/TCOF-MS: Calc. for $\left.\mathrm{C}_{20} \mathrm{H}_{27} \mathrm{Cl}_{2} \mathrm{ZnN}_{10} \mathrm{O}_{8} \quad\left[\mathrm{Zn}(4)_{2}\right]\left(\mathrm{ClO}_{4}\right)_{2}+1\right]^{+}$671.1. Found: 671.1\%. Solubility: DMSO.

\subsection{4. $\left[\mathrm{Zn}(\mathbf{5})_{2}\right]\left(\mathrm{ClO}_{4}\right)_{2} \cdot \mathrm{MeOH}$}

White solid $(0.53 \mathrm{~g}$, yield $66 \%) . \mathrm{C}_{22} \mathrm{H}_{30} \mathrm{Cl}_{2} \mathrm{~N}_{10} \mathrm{O}_{8} \mathrm{Zn} \cdot \mathrm{MeOH}$ (730.87): Calc. C, 37.80; H, 4.69; N, 19.16. Found: C, 37.86; $\mathrm{H}$ 4.26; N, 19.19\%. ${ }^{1} \mathrm{H}$ NMR ( $d_{6}$-DMSO): $\delta=13.18$ (br s, $\left.1 \mathrm{H}\right), 8.53(\mathrm{~s}$, $2 \mathrm{H}), 7.83(\mathrm{~s}, 2 \mathrm{H}), 7.59(\mathrm{~s}, 2 \mathrm{H}), 7.10(\mathrm{~s}, 2 \mathrm{H}), 6.86(\mathrm{~s}, 2 \mathrm{H}), 3.84(\mathrm{t}$, $4 \mathrm{H}, J=6.0 \mathrm{~Hz}), 3.29(\mathrm{t}, 4 \mathrm{H}, J=5.7 \mathrm{~Hz}), 2.40(\mathrm{~s}, 6 \mathrm{H}), 1.68(\mathrm{t}, 2 \mathrm{H}$, $J=7.0 \mathrm{~Hz}) \mathrm{ppm}$. IR $(\mathrm{KBr}): v=3246,3135,1644,1597,1528,1456$, 1362, 1301, 1241, 1103, 967, 839, $749 \mathrm{~cm}^{-1}$. LC/TCOF-MS: Calc. for $\mathrm{C}_{11} \mathrm{H}_{16} \mathrm{~N}_{5}$ [ligand +1$]^{+}$218.3. Found: $218.1 \%$. Solubility: DMSO.

\subsection{5. $\left[\mathrm{Zn}(6)_{2}\right]\left(\mathrm{ClO}_{4}\right)_{2} \cdot \mathrm{H}_{2} \mathrm{O}$}

White solid (0.53 g, yield 65\%). $\mathrm{C}_{22} \mathrm{H}_{30} \mathrm{Cl}_{2} \mathrm{~N}_{10} \mathrm{O}_{8} \mathrm{Zn} \cdot \mathrm{H}_{2} \mathrm{O}$ (716.84): Calc. C, 36.86; H, 4.50; N, 19.54. Found: C, 37.59; H, 4.25; N, $19.02 \%$. ${ }^{1} \mathrm{H}$ NMR $\left(d_{6}\right.$-DMSO): $\delta=8.54(\mathrm{~s}, 2 \mathrm{H}), 7.75(\mathrm{~s}, 2 \mathrm{H}), 7.60(\mathrm{~s}, 2 \mathrm{H}), 7.26$ $(\mathrm{s}, 2 \mathrm{H}), 7.05(\mathrm{~s}, 2 \mathrm{H}), 6.91(\mathrm{~s}, 2 \mathrm{H}), 4.10(\mathrm{t}, 4 \mathrm{H}, J=7.2 \mathrm{~Hz}), 3.96(\mathrm{~s}, 6 \mathrm{H})$, $3.34(\mathrm{t}, 2 \mathrm{H}, J=6.6 \mathrm{~Hz}), 1.78(\mathrm{t}, 2 \mathrm{H}, J=7.2 \mathrm{~Hz}) \mathrm{ppm}$. IR $(\mathrm{KBr})$ : $v=3607,3135,2958,1639,1531,1496,1451,1418,1381,1291$, 1241, 1094, 944, $847 \mathrm{~cm}^{-1}$. LC/TCOF-MS: Calc. for $\mathrm{C}_{22} \mathrm{H}_{30} \mathrm{ZnN}_{10}$ $\left[\mathrm{Zn}(\mathbf{6})_{2}\right]^{+}$498.3. Found: 497.2\%. Solubility: DMSO.

\subsection{X-ray crystallography}

Data for $\mathbf{2}, 3$ and $\left[\mathrm{Ag}(2)_{2}\right] \mathrm{ClO}_{4}$ were collected at $150 \mathrm{~K}$ on a Bruker APEX II CCD diffractometer. The structures of $\mathbf{2}$ and $\left[\operatorname{Ag}(\mathbf{2})_{2}\right]-$ $\mathrm{ClO}_{4}$ were solved by direct methods and refined by full-matrix least-squares on $\mathrm{F}^{2}$ using all data [10]. All non-hydrogen atoms
Table 1

Crystallographic data for $\mathbf{2 , 3}$ and $\left[\mathrm{Ag}(2)_{2}\right] \mathrm{ClO}_{4}$.

\begin{tabular}{|c|c|c|c|}
\hline & 2 & 3 & {$\left[\mathrm{Ag}(\mathbf{2})_{2}\right] \mathrm{ClO}_{4}$} \\
\hline Formula & $\mathrm{C}_{13} \mathrm{H}_{15} \mathrm{~N}_{3} \mathrm{O}$ & $\mathrm{C}_{10} \mathrm{H}_{13} \mathrm{~N}_{5}$ & $\mathrm{C}_{26} \mathrm{H}_{30} \mathrm{AgClN}_{6} \mathrm{O}_{6}$ \\
\hline$M\left(\mathrm{~g} \mathrm{~mol}^{-1}\right)$ & 229.28 & 203.25 & 665.88 \\
\hline Crystal system & monoclinic & monoclinic & triclinic \\
\hline Space group & $P 2_{1} / c$ & $P 2_{1} / n$ & $P \overline{1}$ \\
\hline$T(\mathrm{~K})$ & $150(2)$ & $150(2)$ & $150(2)$ \\
\hline$a(\AA)$ & $12.3194(11)$ & $8.6001(10)$ & $5.915(7)$ \\
\hline$b(\AA)$ & $5.8438(5)$ & $10.1425(12)$ & $14.369(17)$ \\
\hline$c(\AA)$ & $16.3752(15)$ & $12.3976(14)$ & $16.897(19)$ \\
\hline$\alpha\left({ }^{\circ}\right)$ & 90 & 90 & $79.644(16)$ \\
\hline$\beta\left(^{\circ}\right)$ & $97.963(2)$ & $103.131(2)$ & $83.636(16)$ \\
\hline$\gamma\left({ }^{\circ}\right)$ & 90 & 90 & $88.369(17)$ \\
\hline$V\left(\AA^{3}\right)$ & $1167.52(18)$ & $1053.1(2)$ & $1404(3)$ \\
\hline$Z$ & 4 & 4 & 2 \\
\hline$D_{\text {calc }}\left(\mathrm{g} \mathrm{cm}^{-3}\right)$ & 1.303 & 1.282 & 1.575 \\
\hline Reflections collected & 9584 & 7985 & 5143 \\
\hline Unique reflections & 2753 & 2077 & 5143 \\
\hline$R_{\text {int }}$ & 0.0260 & 0.0267 & 0.0000 \\
\hline Obs. reflections $[I>2 \sigma(I)]$ & 2004 & 1593 & 2701 \\
\hline No. of parameters & 157 & 136 & 365 \\
\hline No. of restraints & 0 & 0 & 353 \\
\hline$R_{1}[I>2 \sigma(I)]$ & 0.0389 & 0.0359 & 0.0723 \\
\hline$w R_{2}$ (all data) & 0.1128 & 0.0885 & 0.1804 \\
\hline Goodness-of-fit (GOF) & 1.006 & 1.091 & 0.972 \\
\hline
\end{tabular}

were refined with anisotropic atomic displacement parameters and the hydrogen atoms bonded to carbon were inserted at calculated positions using a riding model. The hydrogen atom bonded to $\mathrm{O} 1$ in compound $\mathbf{2}$ was located from difference maps and refined with a fixed isotropic thermal parameter. The structure of $\left[\operatorname{Ag}(\mathbf{2})_{2}\right]-$ $\mathrm{ClO}_{4}$ was solved by direct methods and found to be twinned. The twin components were identified (CELL_NOW and TWINABS) and the structure refined on $F^{2}$ using all the reflections (HKLF 5 data) [10]. All non-hydrogen atoms were refined with anisotropic atomic displacement parameters and the hydrogen atoms were inserted at calculated positions using a riding model. Data collection and refinement parameters for all three structures are summarized in Table 1.

\subsection{Biology}

Sterilisation of microbiological equipment and media was carried out at $394 \mathrm{~K}$ and $100 \mathrm{kPa}$ for $15 \mathrm{~min}$. All worktops and benches were sterilised by washing with $70 \%(\mathrm{v} / \mathrm{v})$ ethanol-water prior to use. Flat-bottomed microtitre plates were read using a Bio-Tek Synergy HT plate reader at $540 \mathrm{~nm}$. Fungal cell density was measured using a Neubauer hemocytometer under a light microscope at a magnification of $400 \times$. Bacterial cell density was recorded at an optical density of $600 \mathrm{~nm}$ using an Eppendorf Biophotometer.

Galleria mellonella (larvae of the greater wax moth), in the sixth developmental stage, were obtained from Livefoods Direct Ltd., Sheffield, S25 4JJ, UK. The larvae were stored at $288 \mathrm{~K}$ in wood shavings and used within 3 weeks of delivery. Significance of the larvae survival rates was analysed at $72 \mathrm{~h}$ using the log rank (Mantel-Cox) method utilising GraphPad Prismsoftware (version 5). Three categories of significance were used $(*=p<0.05$, $* *=p<0.01$ and $* * *=p<0.001)$. Pseudomonas aeruginosa ATCC 27853, Methicillin-resistant Staphylococcus aureus (MRSA) and Candida albicans ATCC 10231 were obtained from the American Type Culture Collection (Manassas, VA, USA). S. aureus and Escherichia coli were supplied as clinical isolates by the Clinical Microbiology Laboratory, St. James's Hospital, Dublin, Ireland.

\subsubsection{In vivo toxicity assessment}

Larvae of the insect $G$. mellonella were employed to assess the in vivo cytotoxic tolerance of the test compounds and $\mathrm{AgNO}_{3}$. Such 
larvae have been widely used as a convenient and inexpensive in vivo screening model to assess the toxicity of potential new drugs [11,12]. Ten healthy larvae, weighing between $0.2-0.4 \mathrm{~g}$ and with no cuticle discolouration, were used for each compound. Fresh suspensions or solutions of the free ligands and their $\operatorname{Ag}(\mathrm{I})$, $\mathrm{Zn}(\mathrm{II})$ and $\mathrm{Cu}$ (II) complexes were prepared immediately prior to testing under sterile conditions. Each sample $(0.02 \mathrm{~g})$ was suspended or dissolved in DMSO $(1 \mathrm{~mL})$ and sterile water $(9 \mathrm{~mL})$ was added to yield a stock solution of concentration $2000 \mu \mathrm{g} / \mathrm{mL}$. Each sample was tested across the concentration range 2000$100 \mu \mathrm{g} / \mathrm{mL}$. Using serial dilutions with water, each sample was tested across the concentration range $2000-100 \mu \mathrm{g} / \mathrm{mL}$ and the final concentration of DMSO was ca. $1 \% \mathrm{v} / \mathrm{v}$. Test solution $(20 \mu \mathrm{L})$ was injected into the larvae through the last pro-leg and the larvae were then placed in sterile petri dishes and incubated for $72 \mathrm{~h}$ at $30^{\circ} \mathrm{C}$. Death was assessed by the lack of movement in response to stimulus, together with discolouration of the cuticle. Three different controls were used in this assay: the first was untouched larvae; the second was larvae with the pro-leg pierced with a needle but no solution injected; the third was larvae injected with sterile distilled water $(20 \mu \mathrm{L})$.

\subsubsection{In vitro antimicrobial assessment}

In vitro antimicrobial screening: Minimal growth media (MM) was prepared as previously described [13]. Yeast extract peptone dextrose (YEPD) media was composed of $2 \%(\mathrm{w} / \mathrm{v})$ glucose, $2 \%$ $(\mathrm{w} / \mathrm{v})$ bacteriological peptone and $1 \%(\mathrm{w} / \mathrm{v})$ yeast extract. To solidify the media $2 \%(\mathrm{w} / \mathrm{v})$ bacteriological agar was added when required. Nutrient broth and phosphate buffered saline (PBS) were made up according to the manufacturer's instructions (Scharlau Microbiology and Aldrich, respectively).

In vitro bacterial susceptibility testing: Bacteria were grown on nutrient broth agar plates at $310 \mathrm{~K}$ and maintained at $277 \mathrm{~K}$ for short-term storage. All assays were run in triplicate and on three independent occasions. Complexes with low solubility were tested as fine suspensions. Fresh solutions/suspensions of the test samples were prepared immediately prior to testing. Samples $(0.020 \mathrm{~g})$ were added to DMSO $(1 \mathrm{~mL})$ and then water $(9 \mathrm{~mL})$ was added to give a stock solution/suspension (concentration $2000 \mu \mathrm{g} / \mathrm{mL}$ ). The stock solution $(1 \mathrm{~mL})$ was added to water $(9 \mathrm{~mL})$ to yield a solution/suspension with a concentration of $200 \mu \mathrm{g} / \mathrm{mL}$. Nutrient broth $(100 \mu \mathrm{L})$ was added to each well of a 96-well, flat-bottomed microtitre plate. Water $(100 \mu \mathrm{L})$ was added to column 1 of the plate (negative control with no bacterial cells). Column 2 was the positive control (media with bacterial cells). $100 \mu \mathrm{L}$ of the above complex solution $(200 \mu \mathrm{g} / \mathrm{mL})$ was added to every well in column 3 . Serial dilutions (1:1) were made from column 3-12 to produce a test concentration range of $100-0.2 \mu \mathrm{g} / \mathrm{mL}$. Bacteria were grown overnight to the stationary phase in nutrient broth at $310 \mathrm{~K}$ and $200 \mathrm{rpm}$. The cells were diluted to give an optical density of 0.1 at $\lambda=600 \mathrm{~nm}$. The cell suspension $(100 \mu \mathrm{L})$ was added to every well in columns $2-12$. The completed plates were incubated at $310 \mathrm{~K}$ in a static incubator and the final optical density recorded. $\mathrm{MIC}_{50}$ values (minimum concentration required to inhibit $50 \%$ of cell growth) were then determined and expressed in terms of $\mu \mathrm{M}$ concentration.

In vitro fungal susceptibility testing: $C$. albicans was grown on YEPD agar plates at $310 \mathrm{~K}$ and maintained at $277 \mathrm{~K}$ for short-term storage. All assays were run in triplicate and on three independent occasions. Fresh solutions/suspensions of test samples were prepared immediately prior to testing. Samples $(0.020 \mathrm{~g})$ were dissolved/suspended in DMSO $(1 \mathrm{~mL})$ and added to water $(9 \mathrm{~mL})$ to give a stock solution (concentration $2000 \mu \mathrm{g} / \mathrm{mL}$ ). The stock solution/suspension $(1 \mathrm{~mL})$ was added to water $(9 \mathrm{~mL})$ to give a solution with a concentration of $200 \mu \mathrm{g} / \mathrm{mL}$. MM $(100 \mu \mathrm{L})$ was added to each well of a 96 -well, round bottomed microtitre plate. Water
$(100 \mu \mathrm{L})$ was added to column 1 of the plate (negative control, media with no fungal cells). Column 2 was the positive control (media and fungal cells only). $100 \mu \mathrm{L}$ of the above complex solution $(200 \mu \mathrm{g} / \mathrm{mL})$ was added to every well in column 3 . Serial dilutions (1:1) were made from columns $3-12$ to produce a test concentration range of $100-0.2 \mu \mathrm{g} / \mathrm{mL}$.

C. albicans was grown to the stationary phase overnight at $310 \mathrm{~K}$ on YEPD media. The cells were washed with PBS solution and re-suspended in MM at a density of $5 \times 10^{5}$ cells $/ \mathrm{mL}$. The cell suspension $(100 \mu \mathrm{L})$ was added to every well in columns $2-12$. The completed plate was then covered to prevent dehydration. The plate was incubated at $310 \mathrm{~K}$ with continuous shaking for $24 \mathrm{~h}$. The optical density $(\lambda=540 \mathrm{~nm})$ of each well was then recorded. $\mathrm{MIC}_{80}$ value ranges were then determined and expressed in terms of $\mu \mathrm{M}$ concentration.

\section{Results and discussion}

\subsection{Ligand synthesis}

The Schiff base ligands 2-6 (Fig. 1) were formed in high yield by the reaction of 1-(3-aminopropyl)imidazole (Apim) with salicylaldehyde and the various imidazole aldehydes in dry methanol. Ligand composition was determined by a combination of elemental analyses, mass spectrometry and ${ }^{1} \mathrm{H}$ and ${ }^{13} \mathrm{C}$ NMR and IR spectroscopy. The formation of the Schiff base products was confirmed by ${ }^{1} \mathrm{H}$ NMR spectroscopy (imine proton singlet at ca. $8.2 \mathrm{ppm}$ ) and IR spectroscopy (imine $\mathrm{C}=\mathrm{N}$ band at $c a .1650 \mathrm{~cm}^{-1}$ ).

\subsection{X-ray structures of ligands $\mathbf{2}$ and $\mathbf{3}$}

Although the synthesis of $\mathbf{2}$ has previously been documented $[8,9]$ its X-ray crystal structure was not reported. Crystals of 2 and 3 were grown from saturated methanol solutions of both compounds. The asymmetric units for each compound are shown in Figs. 2 and 4 and selected bond lengths and angles are given in Table 2 . In compound $\mathbf{2}$, there is an intramolecular hydrogen bond between the phenolic hydrogen atom and the imine nitrogen atom (N3).

The packing interactions of $\mathbf{2}$ are illustrated in Fig. 3. There is a $\mathrm{C}-\mathrm{H} \cdots \pi$ bonding interaction between the centroid of each imidazole ring and a hydrogen of the C4 methylene group of the spacer chain of a neighbouring molecule (centroid-H 2.59 $\AA$ ). There is an interplanar angle of $88.76(4)^{\circ}$ between the imidazole and phenol rings but there are no striking $\pi-\pi$ stacking interactions.

In compound 3, the imine bond is clearly located between N3 and $\mathrm{C7}$. There is a hydrogen bond linking $\mathrm{N} 4$ to the imine nitrogen of a neighbouring molecule (2.991(2) A under $1 / 2-x, 1 / 2+y, 1 / 2-z)$, and a weaker bond from the same $\mathrm{NH}$ to $\mathrm{N} 5$ of the same neighbour (3.079(2) $\AA$ ). These interactions link the molecules into chains. There is also a weak $\mathrm{C}-\mathrm{H} \cdots \mathrm{N}$ interaction between $\mathrm{C} 10$ and $\mathrm{N} 1$ (the imidazole lone pair) of a second neighbour (3.38(2) A under

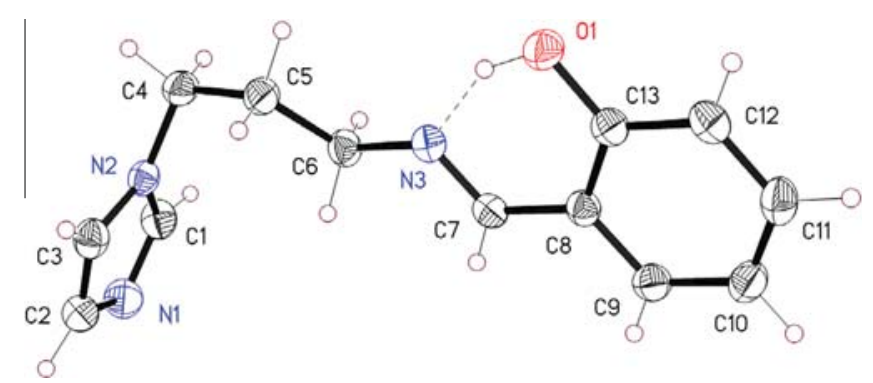

Fig. 2. Asymmetric unit of $\mathbf{2}$ showing intramoleular hydrogen bonding. 


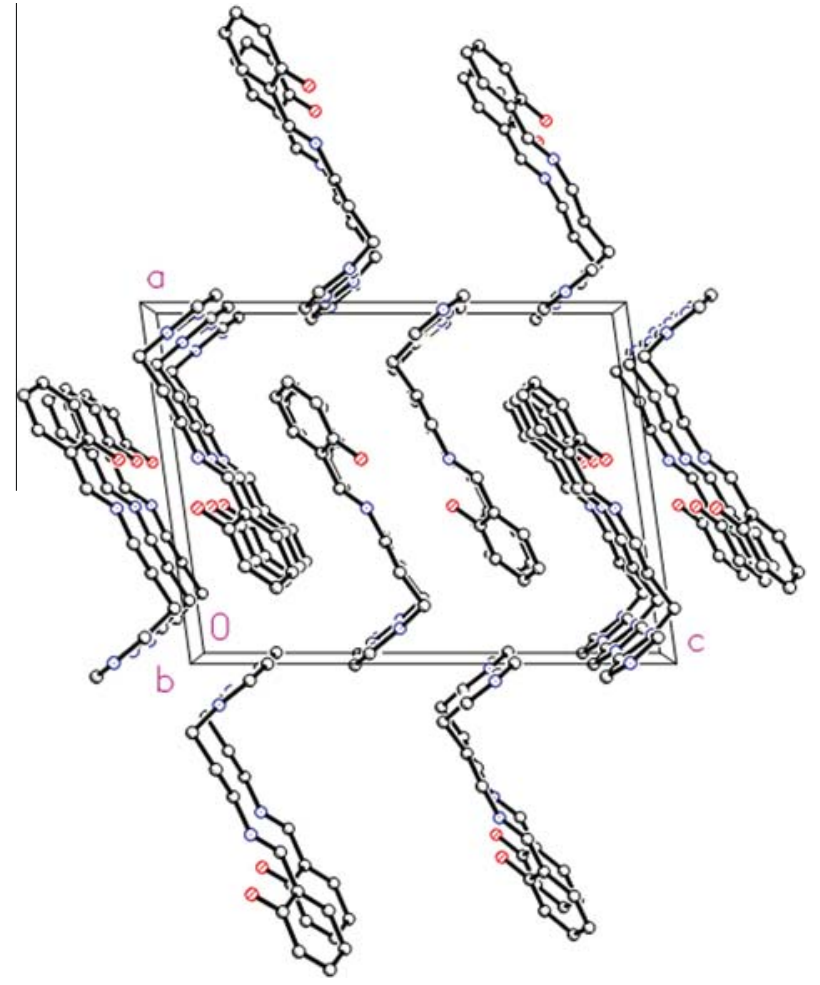

Fig. 3. Packing diagram for 2 .

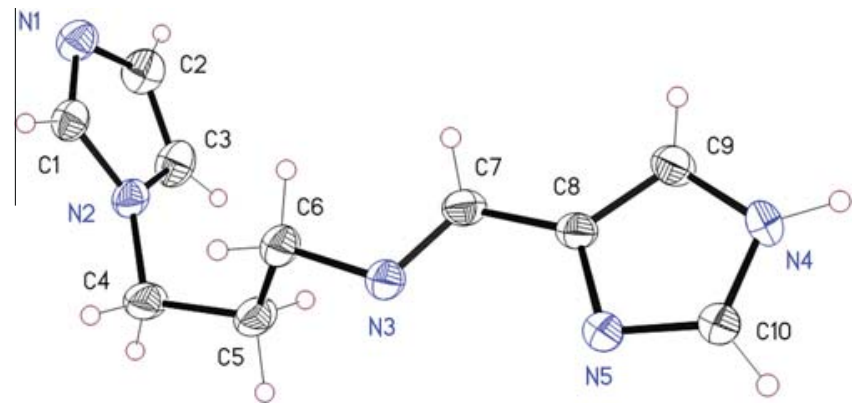

Fig. 4. Asymmetric unit of $\mathbf{3}$.

$x, y, z+1)$ and including this interaction gives sheets of molecules in the plane perpendicular to the $a$ axis (Figs. 5, 6 and Table 2).

\subsection{Metal complex syntheses and characterisation}

The Schiff base ligands (2-6) reacted with $\mathrm{Ag}(\mathrm{I}), \mathrm{Cu}(\mathrm{II})$ and $\mathrm{Zn}(\mathrm{II})$ perchlorate salts at room temperature to give the respective metal complexes in high yield. The five $\mathrm{Ag}(\mathrm{I})$ complexes were reasonably soluble in DMSO. Four of the complexes formulated with a $1: 1$ $\mathrm{Ag}$ :ligand ratio and the remaining complex, $\left[\mathrm{Ag}(2)_{2}\right] \mathrm{ClO}_{4}$, had a $1: 2$ ratio. In the case of the $\mathrm{Cu}(\mathrm{II})$ complexes, four formed with a 1:2 Cu:ligand ratio and the remaining complex, $\left[\mathrm{Cu}(2)_{4}\right]\left(\mathrm{ClO}_{4}\right)_{2}$, had a 1:4 ratio. Repeated attempts to grow crystals of the latter complex proved unsuccessful. All of the $\mathrm{Zn}(\mathrm{II})$ complexes had a 1:2 $\mathrm{Zn}$ :ligand ratio, with $\left[\mathrm{Zn}(\mathbf{2})\left(\mathbf{2}^{-}\right)\right]\left(\mathrm{ClO}_{4}\right)$ being unusual in that this was the only complex in which one of the Schiff base ligands deprotonated $\left(\mathbf{2}^{-}\right)$at the salicylate O-H moiety. Kalanithi et al. [8] previously reported the synthesis of $\mathrm{Cu}(\mathrm{II}), \mathrm{Zn}(\mathrm{II}), \mathrm{Co}(\mathrm{II}), \mathrm{Ni}(\mathrm{II})$ and $\mathrm{Cd}(\mathrm{II})$ complexes of $\mathbf{2}$, formed by reacting the appropriate metal chloride salt with 2 in a 1:1 M ratio. Their $\mathrm{Cu}(\mathrm{II})$ and $\mathrm{Zn}(\mathrm{II})$ complexes formulated as $\left[\mathrm{Cu}\left(\mathbf{2}^{-}\right) \mathrm{Cl}\right]$ and $\left[\mathrm{Zn}\left(\mathbf{2}^{-}\right) \mathrm{Cl}\left(\mathrm{H}_{2} \mathrm{O}\right)_{2}\right]$, showing that there was deprotonation of the salicylate $\mathrm{OH}$ moiety of the single Schiff base ligand and coordination of the chloride ion.
Table 2

Selected bond lengths $[\AA]$ and angles $\left[{ }^{\circ}\right]$ for $\mathbf{2}, 3$ and $\left[\mathrm{Ag}(2)_{2}\right] \mathrm{ClO}_{4}$.

\begin{tabular}{llll}
\hline & $\mathbf{2}$ & $\mathbf{3}$ & {$\left[\mathrm{Ag}(2)_{2}\right] \mathrm{ClO}_{4}$} \\
\hline $\mathrm{C}(1)-\mathrm{N}(1)$ & $1.3172(19)$ & $1.317(2)$ & $1.318(15)$ \\
$\mathrm{C}(1)-\mathrm{N}(2)$ & $1.3501(17)$ & $1.350(2)$ & $1.326(15)$ \\
$\mathrm{N}(1)-\mathrm{C}(2)$ & $1.372(2)$ & $1.371(2)$ & $1.368(14)$ \\
$\mathrm{C}(3)-\mathrm{N}(2)$ & $1.3683(16)$ & $1.366(2)$ & $1.347(14)$ \\
$\mathrm{N}(2)-\mathrm{C}(4)$ & $1.4609(17)$ & $1.462(2)$ & $1.473(14)$ \\
$\mathrm{C}(6)-\mathrm{N}(3)$ & $1.4613(17)$ & $1.4617(19)$ & $1.476(15)$ \\
$\mathrm{N}(3)-\mathrm{C}(7)$ & $1.2756(16)$ & $1.272(2)$ & $1.244(14)$ \\
$\mathrm{C}(9)-\mathrm{N}(4)$ & - & $1.350(2)$ & - \\
$\mathrm{N}(4)-\mathrm{C}(10)$ & - & $1.350(2)$ & - \\
$\mathrm{C}(10)-\mathrm{N}(5)$ & - & $1.314(2)$ & - \\
$\mathrm{C}(13)-\mathrm{O}(1)$ & $1.3531(16)$ & - & $1.349(15)$ \\
$\mathrm{Ag}(1)-\mathrm{N}(1)$ & - & - & $2.109(10)$ \\
$\mathrm{N}(1)-\mathrm{C}(1)-\mathrm{N}(2)$ & $112.66(13)$ & $112.39(15)$ & $113.5(12)$ \\
$\mathrm{C}(1)-\mathrm{N}(1)-\mathrm{C}(2)$ & $104.04(12)$ & $104.33(14)$ & $103.1(11)$ \\
$\mathrm{C}(1)-\mathrm{N}(2)-\mathrm{C}(3)$ & $106.65(12)$ & $106.41(14)$ & $106.1(11)$ \\
$\mathrm{C}(1)-\mathrm{N}(2)-\mathrm{C}(4)$ & $126.95(12)$ & $127.34(14)$ & $124.5(10)$ \\
$\mathrm{C}(3)-\mathrm{N}(2)-\mathrm{C}(4)$ & $126.22(12)$ & $126.23(14)$ & $129.4(11)$ \\
$\mathrm{C}(7)-\mathrm{N}(3)-\mathrm{C}(6)$ & $109.95(11)$ & $118.10(13)$ & $118.2(11)$ \\
$\mathrm{C}(10)-\mathrm{N}(4)-\mathrm{C}(9)$ & - & $107.01(12)$ & - \\
$\mathrm{N}(5)-\mathrm{C}(10)-\mathrm{N}(4)$ & - & $112.59(14)$ & - \\
$\mathrm{C}(10)-\mathrm{N}(5)-\mathrm{C}(8)$ & - & $104.38(13)$ & - \\
\hline & & &
\end{tabular}

The IR spectra of all of the present complexes contained bands associated with perchlorate anions ( $c a .1100$ and $625 \mathrm{~cm}^{-1}$ ). However, it was difficult to see in many of the spectra of the metal complexes if there was a shift in the imine band $\left(c a .1650 \mathrm{~cm}^{-1}\right)$ due to the complexity of the bands in the region. Several major differences were observed between the ${ }^{1} \mathrm{H}$ NMR spectra of the free ligands in $\mathrm{d}_{6}$-DMSO and those of the $\mathrm{Ag}(\mathrm{I})$ and $\mathrm{Zn}(\mathrm{II})$ complexes of the same ligands. In all cases, the $\mathrm{H}-\mathrm{C}=\mathrm{N}$ proton signal corresponding to the imine of the chain was significantly shifted in the metal complexes, suggesting that binding of the metal ion at this $\mathrm{N}$ atom was occurring. Furthermore, there were also shifts in the signals associated with the imidazole ring systems, again indicating possible binding at the imidazole pyridine-type $\mathrm{N}$ atom. Interestingly, there was no loss of the phenolic proton signal $(13.28 \mathrm{ppm})$ in the spectrum of $\left[\mathrm{Ag}(2)_{2}\right] \mathrm{ClO}_{4}$, implying that deprotonation of the phenol group did not occur. The signal for the imidazole ring $\mathrm{N}-\mathrm{H}$ proton in the spectra of the free ligands 3-5 becomes sharper and gets shifted upfield in the spectra of the $\mathrm{Ag}(\mathrm{I})$ or $\mathrm{Zn}(\mathrm{II})$ complexes containing these ligands.

Crystals of $\left[\mathrm{Ag}(\mathbf{2})_{2}\right] \mathrm{ClO}_{4}$ suitable for X-ray crystallographic studies were grown from a hot acetonitrile solution of the complex. The complex contains two independent silver ions, each on a centre of symmetry, so the asymmetric unit contains two half-molecules and one perchlorate anion (Fig. 7 and Table 2). The $\mathrm{Ag}(\mathrm{I})$ ion is bonded, with linear coordination, to the imidazole nitrogen donors and there is also intramolecular hydrogen bonding between the phenolic hydrogen atoms and the imine nitrogen atoms in the chains (N3A and N3B). Fig. 8 shows the resulting structure; alternating independent $\left[\operatorname{Ag}(\mathbf{2})_{2}\right]^{+}$cations are linked into chains by the perchlorate anions which are weakly bonded to the metal ions. The anion acts as a bidentate ligand to $\mathrm{Ag} 1$ (O13-Ag1 and O14-Ag1 $3.424(10)$ and 3.277(7) $\AA$, respectively) and as a monodentate ligand to Ag2 (O12-Ag2, 2.895(8) A). The N1A-Ag1-Ag2-N1B torsion angle is $113.6^{\circ}$. Between the chains there are weak hydrogen bonds between $01 \mathrm{a}$ and its equivalent under symmetry operation.

The X-ray structures of three $\mathrm{Ag}(\mathrm{I})$ complexes of $\mathbf{3}$ have previously been reported [7]. $\left[\mathrm{Ag}_{2}(3)_{2}\right]\left(\mathrm{NO}_{3}\right)_{2}$ formed as an infinite 1D chain polymer where each of the two $\mathrm{Ag}(\mathrm{I})$ ions have different coordination environments, with one metal chelated by the imine $\mathrm{N}$ in the linker chain between the two imidazoles and the pyridinetype $\mathrm{N}$ on the imidazole ring closest to it, with the second metal bonded to the pyridine-type $\mathrm{N}$ on the imidazole ring at the further 


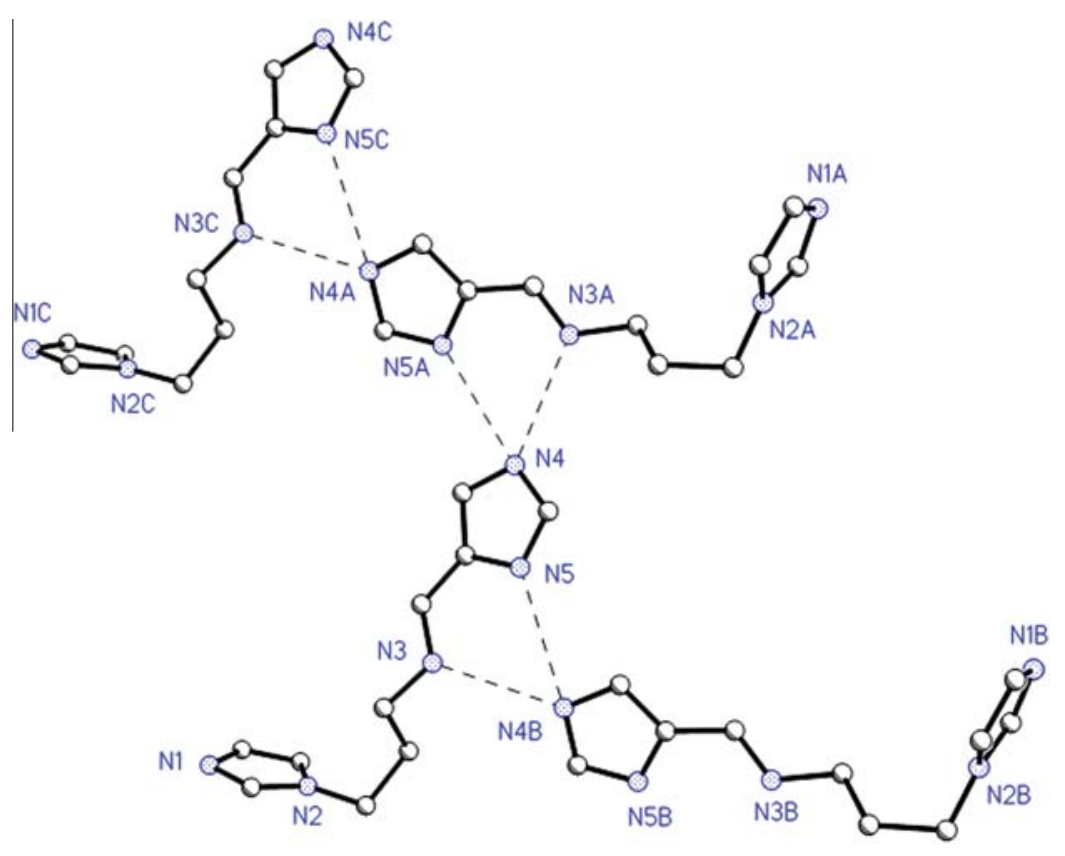

Fig. 5. Partial packing diagram of $\mathbf{3}$ showing hydrogen bonds linking the molecules into chains.

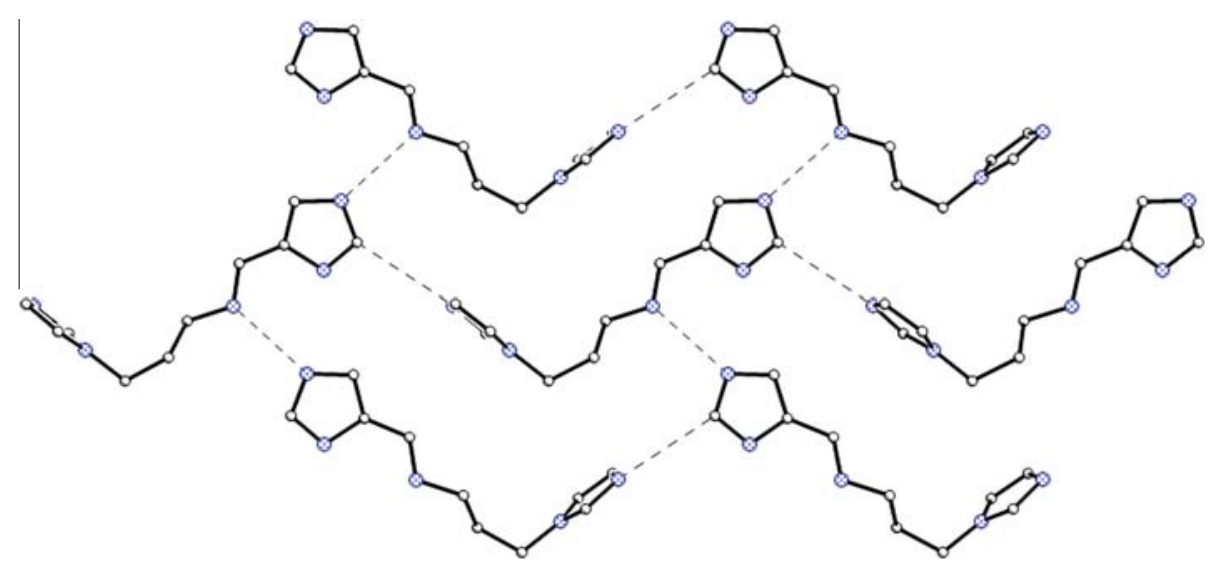

Fig. 6. Packing diagram of $\mathbf{3}$ showing sheets perpendicular to a.

end of the ligand and the $\mathrm{N}$ from the same ring on an adjacent ligand molecule. In the 2D polymeric network of $\left[\mathrm{Ag}_{2}(3)_{2}\right]\left(\mathrm{BF}_{4}\right)_{2}$ there are two crystallographically independent $\mathrm{Ag}(\mathrm{I})$ centres having the same coordination environment, with each metal coordinated by three $\mathrm{N}$ atoms from two different molecules of $\mathbf{3}$ (chelation by the imine $\mathrm{N}$ in the linker chain between the two imidazoles and the pyridine-type $\mathrm{N}$ on the closest imidazole ring, and by the pyridine-type $\mathrm{N}$ on the imidazole ring at the opposite end of an adjacent ligand molecule). $\left[\mathrm{Ag}_{2}(3)_{2}\right]\left(\mathrm{CH}_{3} \mathrm{CO}_{2}\right)_{2}$ features a discrete $\left[\mathrm{Ag}_{2}(3)_{2}\right]^{2+}$ molecular ring with each metal triangularly coordinated by three $\mathrm{N}$ atoms from two different molecules of $\mathbf{3}$ (same set of donor atoms as in $\left.\left[\mathrm{Ag}_{2}(\mathbf{3})_{2}\right]\left(\mathrm{BF}_{4}\right)_{2}\right)$. In the electrospray mass spectrum of $\left[\mathrm{Ag}_{2}(3)_{2}\right]\left(\mathrm{NO}_{3}\right)_{2}$ the authors report signals for $[\mathrm{Ag}(3)]^{+}$ (310.3), $\left[\mathrm{Ag}(3)_{2}\right]^{+}$(512.8), $\left[\mathrm{Ag}_{2}(\mathbf{3})_{2}\right]\left(\mathrm{NO}_{3}\right)_{2}{ }^{+}(683.6)$. In the mass spectrum of the present complex, $[\mathrm{Ag}(\mathbf{3})] \mathrm{ClO}_{4}$, we observe a large peak for the $[\operatorname{Ag}(\mathbf{3})]^{+}$species and a much smaller peak for $\left[\operatorname{Ag}(3)_{2}\right]^{+}$.

\subsection{Biology}

\subsubsection{Toxicity profiling}

Larvae of the insect, G. mellonella, were used to assess the in vivo toxicity of the test compounds (Table 3). At the maximum admin- istered dosage of the free ligands (ca. $0.2 \mu \mathrm{mol}$ ), none of the larvae died, except in the case of ligand $\mathbf{6}$, where $10 \%$ of the larvae expired. These findings suggest that the ligands do not pose significant toxicity issues to the insect. In addition, all of the $\mathrm{Cu}(\mathrm{II})$ and $\mathrm{Zn}(\mathrm{II})$ complexes displayed minimal toxicity. $\left[\mathrm{Ag}(\mathbf{2})_{2}\right] \mathrm{ClO}_{4}$ and $[\mathrm{Ag}(\mathbf{3})] \mathrm{ClO}_{4}$ were less well tolerated, and both of these complexes proved to be more destructive than $\mathrm{AgNO}_{3}$, where significant toxicity $(30 \%)$ was only evident at the much higher dosage of $0.235 \mu \mathrm{mol}$. It is interesting to note that, whereas $[\mathrm{Ag}(3)] \mathrm{ClO}_{4}$ was quite toxic at the $0.197 \mu \mathrm{mol}$ dosage level $(90 \%$ mortality), the complex containing the isomeric ligand, 4 (i.e. $\left.[\mathrm{Ag}(\mathbf{4})] \mathrm{ClO}_{4} \cdot \mathrm{MeOH}\right)$, did not cause any fatalities at this dose.

\subsubsection{Antimicrobial activity}

The free ligands and the $\mathrm{Cu}(\mathrm{II})$ and $\mathrm{Zn}$ (II) complexes were essentially inactive against all of the test microbes. The lack of activity found for uncoordinated ligand 2 and its $\mathrm{Cu}(\mathrm{II})$ and $\mathrm{Zn}$ (II) complexes is similar to that previously reported [8] for $[\mathrm{Cu}(\mathbf{2}) \mathrm{Cl}]$ and $\left[\mathrm{Zn}(\mathbf{2}) \mathrm{Cl}\left(\mathrm{H}_{2} \mathrm{O}\right)_{2}\right]$ against the same organisms (except MRSA, which was not tested). In contrast to the relative inactivity of $\mathbf{2}$, a related Schiff base, formed from Apim and 2-formylphenoxyacetic acid, was found to be quite active in its uncoordinated form against 

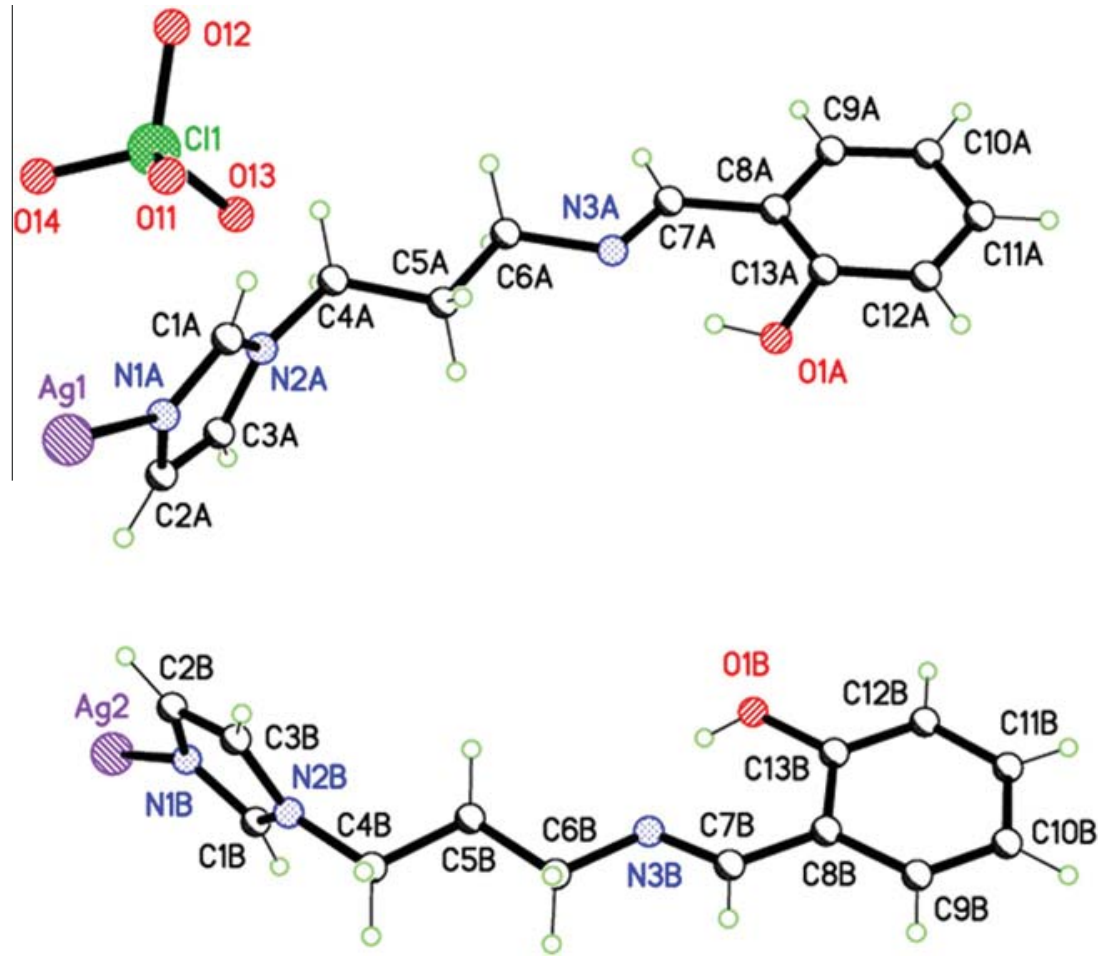

Fig. 7. Asymmetric unit of $\left[\mathrm{Ag}(2)_{2}\right] \mathrm{ClO}_{4}$ containing two half-molecules and one anion.

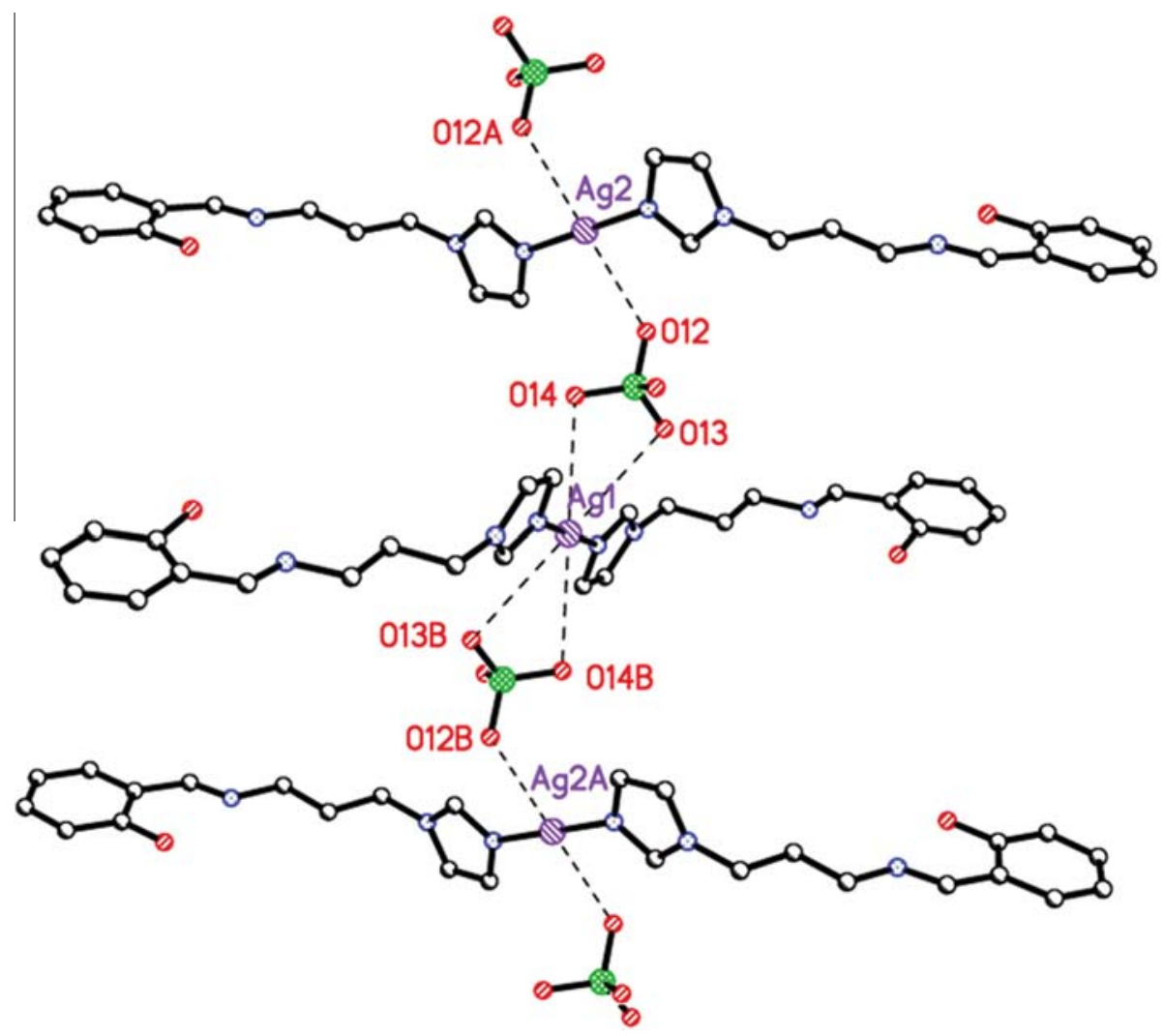

Fig. 8. Partial packing diagram of $\left[\mathrm{Ag}(2)_{2}\right] \mathrm{ClO}_{4}$ showing interactions between $\mathrm{Ag}(\mathrm{I})$ cations and perchlorate anions.

strains of S. aureus and E. Coli (MIC 100 value of $6.25 \mu \mathrm{g} / \mathrm{ml}$ in each case), indicating the importance of functionalization of the salicylate phenyl ring [14]. In addition, the lack of antimicrobial potency of the present $\mathrm{Cu}(\mathrm{II})$ complexes differs markedly from that of $\left[\mathrm{CuL}\left(\mathrm{H}_{2} \mathrm{O}\right)_{3}\right] \mathrm{Cl} \cdot 2 \mathrm{H}_{2} \mathrm{O}$ ( $\mathrm{LH}$ is a Schiff base ligand derived from L-histidine and pyrrole-2-carboxaldehyde) [15], which proved to be 
Table 3

Mortality (\%) of G. mellonella larvae $72 \mathrm{~h}$ post injection with various amounts of the test compounds.

\begin{tabular}{|c|c|c|c|c|c|}
\hline \multirow[t]{2}{*}{ Compound } & \multirow[t]{2}{*}{$\mu \mathrm{g} /$ larvae } & \multicolumn{4}{|c|}{ Administered amount/\% mortality } \\
\hline & & 40 & 20 & 10 & 2 \\
\hline 2 & & $0.175 / 0$ & $0.087 / 0$ & $0.044 / 0$ & $0.009 / 0$ \\
\hline$\left[\mathrm{Ag}(2)_{2}\right] \mathrm{ClO}_{4}$ & $\mu \mathrm{mol}$ & $0.060 / 80$ & $0.030 / 10$ & $0.015 / 0$ & $0.003 / 0$ \\
\hline$\left[\mathrm{Cu}(2)_{4}\right]\left(\mathrm{ClO}_{4}\right)_{2}$ & $\mu \mathrm{mol}$ & $0.034 / 0$ & $0.017 / 0$ & $0.009 / 0$ & $0.002 / 0$ \\
\hline$\left[\mathrm{Zn}(2)\left(2^{-}\right)\right]\left(\mathrm{ClO}_{4}\right)$ & $\mu \mathrm{mol}$ & $0.034 / 0$ & $0.017 / 0$ & $0.009 / 0$ & $0.002 / 0$ \\
\hline 3 & $\mu \mathrm{mol}$ & $0.197 / 0$ & $0.098 / 0$ & $0.049 / 0$ & $0.010 / 0$ \\
\hline$[\mathrm{Ag}(3)] \mathrm{ClO}_{4}$ & $\mu \mathrm{mol}$ & $0.097 / 90$ & $0.049 / 0$ & $0.024 / 0$ & $0.005 / 0$ \\
\hline$\left[\mathrm{Cu}(3)_{2}\right]\left(\mathrm{ClO}_{4}\right)_{2} \cdot \mathrm{H}_{2} \mathrm{O}$ & $\mu \mathrm{mol}$ & $0.058 / 20$ & $0.029 / 10$ & $0.015 / 0$ & $0.003 / 0$ \\
\hline$\left[\mathrm{Zn}(3)_{2}\right]\left(\mathrm{ClO}_{4}\right)_{2}$ & $\mu \mathrm{mol}$ & $0.060 / 10$ & $0.030 / 10$ & $0.015 / 0$ & $0.003 / 0$ \\
\hline 4 & $\mu \mathrm{mol}$ & $0.189 / 0$ & $0.094 / 0$ & $0.047 / 0$ & $0.009 / 0$ \\
\hline$[\mathrm{Ag}(4)] \mathrm{ClO}_{4}$ & $\mu \mathrm{mol}$ & $0.097 / 0$ & $0.049 / 0$ & $0.024 / 0$ & $0.005 / 0$ \\
\hline$\left[\mathrm{Cu}(4)_{2}\right]\left(\mathrm{ClO}_{4}\right)_{2}$ & $\mu \mathrm{mol}$ & $0.060 / 10$ & $0.030 / 0$ & $0.015 / 0$ & $0.003 / 0$ \\
\hline$\left[\mathrm{Zn}(4)_{2}\right]\left(\mathrm{ClO}_{4}\right)_{2} \cdot \mathrm{H}_{2} \mathrm{O}$ & $\mu \mathrm{mol}$ & $0.060 / 0$ & $0.030 / 0$ & $0.015 / 0$ & $0.003 / 0$ \\
\hline 5 & $\mu \mathrm{mol}$ & $0.184 / 0$ & $0.092 / 0$ & $0.046 / 0$ & $0.009 / 0$ \\
\hline$[\mathrm{Ag}(5)] \mathrm{ClO}_{4}$ & $\mu \mathrm{mol}$ & $0.094 / 20$ & $0.047 / 10$ & $0.024 / 0$ & $0.005 / 0$ \\
\hline$\left[\mathrm{Cu}(5)_{2}\right]\left(\mathrm{ClO}_{4}\right)_{2}$ & $\mu \mathrm{mol}$ & $0.057 / 10$ & $0.029 / 0$ & $0.014 / 0$ & $0.003 / 0$ \\
\hline$\left[\mathrm{Zn}(5)_{2}\right]\left(\mathrm{ClO}_{4}\right)_{2} \cdot \mathrm{MeOH}$ & $\mu \mathrm{mol}$ & $0.055 / 0$ & $0.027 / 0$ & $0.014 / 0$ & $0.003 / 0$ \\
\hline 6 & $\mu \mathrm{mol}$ & $0.184 / 10$ & $0.092 / 0$ & $0.046 / 0$ & $0.009 / 0$ \\
\hline$[\mathrm{Ag}(6)] \mathrm{ClO}_{4}$ & $\mu \mathrm{mol}$ & $0.094 / 0$ & $0.047 / 0$ & $0.024 / 0$ & $0.005 / 0$ \\
\hline$\left[\mathrm{Cu}(6)_{2}\right]\left(\mathrm{ClO}_{4}\right)_{2} \cdot \mathrm{H}_{2} \mathrm{O}$ & $\mu \mathrm{mol}$ & $0.057 / 0$ & $0.029 / 0$ & $0.014 / 0$ & $0.003 / 0$ \\
\hline$\left[\mathrm{Zn}(6)_{2}\right]\left(\mathrm{ClO}_{4}\right)_{2} \cdot \mathrm{H}_{2} \mathrm{O}$ & $\mu \mathrm{mol}$ & $0.056 / 0$ & $0.028 / 10$ & $0.014 / 0$ & $0.003 / 0$ \\
\hline $\mathrm{AgNO}_{3}$ & $\mu \mathrm{mol}$ & $0.235 / 30$ & $0.118 / 10$ & $0.059 / 0$ & $0.012 / 0$ \\
\hline
\end{tabular}

Table 4

Antimicrobial activitiy ranges of the $\mathrm{Ag}(\mathrm{I})$ complexes and $\mathrm{AgNO}_{3}$. $\mathrm{MIC}_{50}$ (bacteria) and $\mathrm{MIC}_{80}$ (fungi) values are expressed in $\mu \mathrm{M}$ concentrations of the samples.

\begin{tabular}{|c|c|c|c|c|c|}
\hline \multirow[t]{2}{*}{ Complex } & \multicolumn{4}{|l|}{$\mathrm{MIC}_{50}(\mu \mathrm{M})$} & \multirow{2}{*}{$\begin{array}{l}\mathrm{MIC}_{80}(\mu \mathrm{M}) \\
\text { C. albicans }\end{array}$} \\
\hline & S. aureus & MRSA & E. coli & P. aeruginosa & \\
\hline$\left[\mathrm{Ag}(\mathbf{2})_{2}\right] \mathrm{ClO}_{4}$ & $37.5-75$ & $37.5-75$ & $37.5-75$ & $37.5-75$ & $9.4-18.8$ \\
\hline$[\mathrm{Ag}(\mathbf{3})] \mathrm{ClO}_{4}$ & $60.9-121.8$ & $60.9-121.8$ & $60.9-121.8$ & $30.5-60.9$ & $7.6-15.2$ \\
\hline$[\mathrm{Ag}(4)] \mathrm{ClO}_{4}$ & $56.5-113$ & $28.3-56.6$ & $56.5-113$ & $14.2-28.3$ & $7.6-15.2$ \\
\hline$[\mathrm{Ag}(\mathbf{5})] \mathrm{ClO}_{4}$ & $58.9-117.8$ & $58.9-117.8$ & $58.9-117.8$ & $29.5-58.9$ & $14.7-29.4$ \\
\hline$[\mathrm{Ag}(\mathbf{6})] \mathrm{ClO}_{4}$ & $58.9-117.8$ & $58.9-117.8$ & $58.9-117.8$ & $58.9-117.8$ & $58.9-117.8$ \\
\hline $\mathrm{AgNO}_{3}$ & $36.8-73.6$ & $36.8-73.6$ & $73.6-147.2$ & $18.4-36.8$ & $9.2-18.4$ \\
\hline
\end{tabular}

quite active against $E$. coli and C. albicans $\left(\mathrm{MIC}_{100}=11.9\right.$ and $19.0 \mu \mathrm{M}$, respectively). The $\mathrm{Zn}(\mathrm{II})$ complex of the same ligand, $\left[\mathrm{ZnL}\left(\mathrm{H}_{2} \mathrm{O}\right)\right] \mathrm{Cl}$, was essentially inactive.

The anti-bacterial and anti-fungal activities of the new $\operatorname{Ag}(\mathrm{I})$ complexes and the positive control, $\mathrm{AgNO}_{3}$, are listed in Table 4 . $[\mathrm{Ag}(\mathbf{6})] \mathrm{ClO}_{4}$ was the least active across all of the microbial species, and the activities of the other water-insoluble $\mathrm{Ag}(\mathrm{I})$ complexes were similar to that observed for water-soluble $\mathrm{AgNO}_{3}$. In these cases, activity against the fungal pathogen, C. albicans, was greater than that for bacterial pathogens, which is a trend similar to that previously reported for other $\mathrm{Ag}(\mathrm{I})$ complexes [5,6,16]. Although there was no clear discriminatory trends observed in activities between Gram-positive ( $S$. aureus and MRSA) and Gram-negative (E. coli and P. aeruginosa) bacteria, most of the complexes, and especially $[\mathrm{Ag}(\mathbf{4})] \mathrm{ClO}_{4} \cdot \mathrm{MeOH}$, were more cytotoxic against $P$. aeruginosa. The growth inhibitory effects of the present $\mathrm{Ag}(\mathrm{I})$ imidazole Schiff base complexes against MRSA and E. coli are similar to those recently documented for a series of $\mathrm{Ag}(\mathrm{I})$ complexes of 9-anthracenecarboxylic acid containing non-Schiff base imidazole ligands and also the clinically used compound, silver sulphadiazine [6]. However, some of the latter complexes displayed significantly greater anti-Candida activity compared to the present complexes. In addition, the present $\operatorname{Ag}(\mathrm{I})$ complexes had activities similar to that of the prescription drug, miconazole $\left(\mathrm{MIC}_{90}\right.$ against C. albicans $=19 \mu \mathrm{M}[17]$ ).

Although there are close similarities in the antimicrobial activities of the new $\operatorname{Ag}(\mathrm{I})$ complexes with that of the simple $\mathrm{Ag}(\mathrm{I})$ salt, $\mathrm{AgNO}_{3}$, it would appear that, from a therapeutic viewpoint, some of complexes, and particularly $[\mathrm{Ag}(4)] \mathrm{ClO}_{4} \cdot \mathrm{MeOH}$, are considerably less toxic than $\mathrm{AgNO}_{3}$ towards the in vivo model, G. mellonella.

\section{Conclusions}

Schiff base ligands form readily and in high yield upon reacting Apim with salicylaldehyde and imidazole aldehydes. These Schiff bases readily coordinate to $\mathrm{Ag}(\mathrm{I}), \mathrm{Cu}(\mathrm{II})$ and $\mathrm{Zn}(\mathrm{II})$ centres. Encouragingly, all of free ligands and most of their metal complexes are relatively non-toxic, in vivo, towards G. mellonella. Whereas the uncoordinated ligands and the $\mathrm{Cu}(\mathrm{II})$ and $\mathrm{Zn}(\mathrm{II})$ complexes are inactive against a selection of microbial pathogens, most of the $\mathrm{Ag}(\mathrm{I})$ complexes, as well as $\mathrm{AgNO}_{3}$, exhibit moderate anti-bacterial activity and good anti-fungal activity.

\section{Appendix A. Supplementary data}

CCDC 916653-916655 contain the supplementary crystallographic data for $\mathbf{2}, 3$ and $\left[\mathrm{Ag}(2)_{2}\right] \mathrm{ClO}_{4}$, respectively. These data can be obtained free of charge via http://www.ccdc.cam.ac.uk/conts/retrieving.html, or from the Cambridge Crystallographic Centre, 12 Union Road, Cambridge CB2 1EZ, UK: fax: (+44) 1223-336-033; or e-mail: deposit@ccdc.cam.ac.uk.

\section{References}

[1] M.B. Ferrari, S. Capacchi, G. Reffo, G. Pelosi, P. Tarasconi, R. Albertini, S. Pinelli, P. Lunghi, J. Inorg. Biochem. 81 (2000) 89.

[2] J. Charo, J.A. Lindencrona, L.M. Carlson, J. Hinkula, J. Virol. 78 (2004) 11321.

[3] M. Wang, L.F. Wang, Y.Z. Li, Q.X. Li, Z.D. Xu, D.Q. Qu, Trans. Met. Chem. 26 (2001) 307.

[4] M.A. Neelakantan, F. Rusalraj, J. Dharmaraja, S. Johnsonraja, T. Jeyakumarb, M. Sankaranarayan Pillai, Spectrochim. Acta, Part A 71 (2008) 1599.

[5] R. Rowan, T. Tallon, A.M. Sheahan, R. Curran, M. McCann, K. Kavanagh, M. Devereux, V. McKee, Polyhedron 25 (2006) 1771. 
[6] M. McCann, R. Curran, M. Ben-Shoshan, V. McKee, A.A. Tahir, M. Devereux, K Kavanagh, B.S. Creaven, A. Kellett, J. Chem, Dalton Trans. 41 (2012) 6516.

[7] X.-H. Lu, Y.-Q. Huang, L.-Y. Kong, T.-A. Okamura, W.-Y. Sun, N. Ueyama, Z Anorg. Allg. Chem. 633 (2007) 2064.

[8] M. Kalanithi, M. Rajarajan, P. Tharmaraj, J. Coord. Chem. 64 (2011) 842.

[9] A. Ouadi, B. Gadenne, P. Hesemann, J.J.E. Moreau, I. Billard, C. Gaillard, S. Mekki, G. Moutiers, Chem. Eur. J. 12 (2006) 3074.

[10] G.M. Sheldrick, Acta Crystallogr., Sect. A 64 (2008) 112.

[11] A.P. Desbois, P.J. Coote, Adv. Appl. Microbiol. 78 (2012) 25.

[12] A. Kellett, M. O'Connor, M. McCann, O. Howe, A. Casey, P. McCarron, K Kavanagh, M. McNamara, S. Kennedy, D.D. May, P.S. Skell, D. O'Shea, M. Devereux, Med. Chem. Commun. 2 (2011) 579.
[13] R. Curran, J. Lenehan, M. McCann, K. Kavanagh, M. Devereux, D.A. Egan, G. Clifford, K. Keane, B.S. Creaven, V. McKee, Inorg. Chem. Commun. 10 (2007) 1149.

[14] A. Iqbal, H. Latif Siddiqui, C.M. Ashraf, M. Ahmed, G.W. Weaver, Macromolecules 12 (2007) 245.

[15] D. Arish, M. Sivasankaran Nair, Arab. J. Chem. 5 (2012) 179.

[16] M. McCann, A.S Santos, B.A da Silva, MTV Romanos, A.S Pyrrho, M Devereux, K. Kavanagh, I. Fichtner, A. Kellett, Toxicol. Res. 1 (2012) 47.

[17] A. Eshwika, B. Coyle, M. Devereux, M. McCann, K. Kavanagh, BioMetals 17 (2004) 415. 